\title{
Índice de Integración Institucional del Mercado Común Centroamericano (MCCA-RD)*
}

\section{Institutional Integration Index of the Central American Common Market (MCCA-RD)}

\author{
Jorge Alberto Orellana Aragón* * \\ Luiz Augusto Estrella Faria* **
}

\begin{abstract}
Resumo: El objetivo de este artículo fue evaluar la hipótesis de que la integración institucional interacciona con la integración económica regional a través de la elaboración del Índice de Integración Institucional para el caso del Mercado Común Centroamericano (MCCA) e sus resultados fueron comparados para los casos de la Unión Europea (EU) y el MERCOSUR estimados por Dorrucci. Posteriormente, fue aplicado un modelo de Vectores Autoregresivos (VAR) para ese índice incorporando variables como el ingreso per-cápita, términos de comercio y apertura comercial. Los resultados sugieren que una mayor integración institucional trae un nivel más alto de nivel de integración económica y vice-versa.
\end{abstract}

Palavras-Chave: Integración económica. Mercado Común Centroamericano. MCCA. Arreglos institucionales internacionales.

\begin{abstract}
The purpose of this article was evaluated the hypothesis that institutional integration interacts with regional economic integration, was tested developing an institutional integration index for The Central American Common Market and were compared with European Union and Mercosul were estimated by Dorrucci. Subsequently a model of Autoregressive Vectors (VAR) was implemented, incorporating that index to such variables as per-capita income, exchange trading terms and trade opening. The results indicate that greater institutional integration brings a higher level of economic integration and vice versa.
\end{abstract}

Keywords: Economic integration. Central American Common Market. CACM. International institutional arrangements.

JEL Classification: F02; F14; F15; F55.

\footnotetext{
* $\quad$ Artículo presentado en la II Reunión Iberoamericana de Socioeconomía, ocurrida en Porto Alegre, Rio Grande do Sul, en noviembre de 2015.

* Doctor en Economía por el Programa de Pós-Graduação em Economia (PPGE) de la Universidade Federal do Rio Grande do Sul (UFRGS). Profesor del Instituto de Ciências Econômicas, Administrativas e Contábeis (ICEAC) de la Universidade Federal de Rio Grande. E-mail: jorge_ orellana@furg.br

*** Doctor en Economía por el Instituto de Economia de la Universidade Federal do Rio de Janeiro (UFRJ). Profesor del Departamento de Economia e Relações Internacionais da Faculdade de Ciências Econômicas da Universidade Federal do Rio Grande do Sul (UFRGS). E-mail: lufaria@ ufrgs.br
} 


\section{1 lntrodução}

El presente trabajo tiene por objetivo presentar una visión general de la génesis del Mercado Común de América Central (MCCA) fundamentándose en las teorías convencionales desarrolladas por la literatura de la Integración Económica y a partir de allí construir un Índice de Integración Institucional en base al propuesto por Dorrucci et al. (2002) y posteriormente realizar una aplicación empírica de dicho Índice en un modelo de Vectores Autoregresivos (VAR) con otras variables económicas para corroborar si existen relaciones de causalidad que favorezcan la integración económica entre los países comparando sus resultados con las estimaciones realizadas para los casos de la Unión Europea y el Mercosur de Dorrucci et al. (2002).

Revisando la historia y literatura cuando fue creado en Centro América el Mercado Común de América Central (MCCA) su idea estratégica original en los años cincuenta era que el comercio entre los países facilitaría el progreso económico para los Estados miembros. Como resultado natural posteriormente se daría un progreso social cuya consecuencia final sería reducir la dependencia del comercio de exportaciones tradicionales, a través de Modelo de Substitución de Importaciones (MSI), que por su vez seria sustentado por la producción agrícola y principalmente industrial. Todo esto fue basado en el sistema integrado de transportes, incentivando o desarrollo de proyectos industriales, basados en el principio de un crecimiento equilibrado (TREJOS DONALDSON, 1997).

Como apunta Zapata y Pérez Caldentey (2005) esta fase, es llamada de "integración interna", que fue desarrollada siguiendo el plan de la Cepal para toda América Latina. El proceso de integración fue apoyado por una substitución de importaciones regionales como el paso inicial para una eventual "substitución de exportaciones”. Este proceso sucedió en su primera fase en Argentina, Brasil y México durante los años cincuenta y posteriormente en el MCCA cobró impulso entre 1960 y mediados de los años setenta.

A segunda etapa llamada de "la integración para afuera" para el MCCA se considera que formalmente comienza a partir de 1991 y tuvo como objetivo fundamental alcanzar la integración en la economía internacional. En el caso del Mercosur es entre los años 1991-1995 es cuando se considera el inicio de su primera fase con el establecimiento de la Tarifa Externa Común (TEC). Fue una respuesta a la "década perdida" de los años ochenta, cuando muchos los países América

1 Zapata y Caldentey Pérez (2005) hacen referencia a este término, acuñado por la Cepal, como un retroceso de todo lo que fue conseguido en las últimas décadas como la caída en la renta per-cápita. Ella también puede ser incluida en el concepto de que la perdida de grande cambio e innovación, pero, principalmente, la incapacidad física para mantener el llamado Régimen Industrias Centro-Americanas de Integración del MCCA que serán discutidos más adelante en esta tesis, considerando los efectos de la crisis económica global derivado del aumento del precio del 
Latina fueron involucrados en conflictos militares internos como una fase-piloto de confrontación de este a oeste no medio da Guerra Fría. Esta fase es coincidente con el llamado regionalismo abierto por la Comisión Económica para América Latina y el Caribe (1994), donde se buscó a compatibilidad entre la estrategia de desarrollo interna e políticas económicas basadas en la liberalización del comercio, privatización y liberalización financiera.

La posible tercera fase para el MCCA-RD es un proceso de largo plazo y que requieren de acciones definitivas para integración externa en el proceso de globalización mundial, como la profundización de la integración económica intra-regional por medio de desarrollo de sus instituciones (NORTH, 1990) que involucren acciones concretas, además de los acuerdos formales entre los Estados-nación (BANCO INTERAMERICANO DE DESARROLLO; COMISIÓN ECONÓMICA PARA AMÉRICA LATINA 1998; CANDELTEY DEL POZO, 2000). De hecho, esta fase coincide con la segunda fase del Mercosur (1995-98) que es marcada por la depreciación del real y el colapso definitivo del modelo hard peg regime de llamada caja de conversión de Argentina. Posteriormente entre los años 2000-2002 se da la fase tercera llamada de "relanzamiento" y en los años 2004-2008 es llamada la fase de "revitalización".

Por último, vale la pena resaltar que uno de los objetivos fundamentales del Mercosur es evitar la especialización en sectores específicos como lo es el acta de 1986 como una disposición anti-ricardiana llamado como Principio de Equilibrio (FARIA; FIORI, 2011). ${ }^{2}$

\section{Formas, Grados y Rasgos de la Integración Económica}

La integración tiene varias formas o grados de integración como sugieren Balassa (1964), Baumann, Canuto y Gonçalves (2004), y Gilpin (2001). El nivel más básico es llamado "áreas de preferencias comerciales" (APC) que consiste en la reducción o derogación de impuestos de importación en el comercio entre los países involucrados en el no acuerdo, aunque esa ventaja sea apenas para una lista de productos específicos. Por medio de este acuerdo se fomentan facilidades para aumentar un comercio sectorialmente focalizado, en el cual cada país o grupo de países mantienen independencia en su política comercial en relación al resto del mundo, pudiendo haber o no proximidad geográfica entre los países. Por ejemplo, La Iniciativa para la Cuenca del Caribe (ICC), que fue establecida por la administración del presidente de los Estados Unidos Ronald Reagan en la década de

petróleo y de la deuda externa final de los años setenta e inicio de los años ochenta.

2

Los cuatro principios que rigen el Mercosur son gradualismo, flexibilidad, reciprocidad y

equilibrio.

ORELLANA ARAGÓN, J. A.; FARIA, L. A. E. Índice de Integración Institucional del Mercado... 
los años ochenta y destinada para los países de América Central y el Caribe (con excepción de Cuba) y las concesiones comerciales entre Estados Unidos e Israel.

Después como indican Baumann, Canuto y Gonçalves (2004), el siguiente nivel de integración es llamado Área o Zona de Libre Comercio (ALC), una vez que éstas son libres de restricciones cuantitativas. Una ALC necesariamente implica concesiones comerciales generalizadas, que comprenden la totalidad o la pauta comercial entre los países contratantes. En este tipo de acuerdo, cada país preserva su autonomía, con sus propias pautas en relación a otros países, para diseñar su propia política comercial.

De acuerdo con la experiencia internacional, este tipo de acuerdo tiene como función o grado de amplitud y profundidad que demandan dos tipos de providencias para evitar potenciales conflictos y disputas comerciales entre los países socios:

a) definición de las reglas de origen, que definen el porcentual del valor adicionado en los países dela ALC y determinan el producto nacional con el objetivo de evitar la triangulación de productos originarios de terceros países importados por uno de los países miembros del acuerdo; y

b) alineamiento de las tasas de cambio de los países participantes para evitar situaciones en que los países socios pasan a ser sistemáticamente superavitarios en el comercio debido a una devaluación cambiaria. Ejemplos de la ALC están el acuerdo entre Estados Unidos, México y Canadá conocido como Nafta y el tratado entre los países de la América Central y la República Dominicana con Estados Unidos designado con sus siglas como CAFTA.

Un siguiente nivel de integración lo constituye una Unión Aduanera (UA). Como bien destaca Balassa (1964), una UA se constituye en la supresión de las discriminaciones, o sea, se refiere a los movimientos de mercaderías en el interior de unión e igualdad de derechos en relación al comercio con otros países. Por lo tanto, se puede considerar una UA al mismo tiempo una ALC plena entre países miembros, pero con la diferencia o peculiaridad en que los socios tienen un compromiso de definir una política comercial común externa y, en el caso en que se dé una negociación con otros países o bloques económicos, con una sola delegación negociadora.

Balassa (1964) apunta que un Mercado Común alcanza una forma más elevada y adicionada de integración cuando son abolidas no solo las restricciones comerciales, sino también las restricciones a los movimientos plenos de factores productivos entre los países miembros del mercado. En esta forma de integración, además del comercio libre entre los países participantes, también son establecidas barreras externas comunes. O sea, la negociación es realizada en conjunto con terceros países. De esa forma, debe de existir armonización y coordinación de po- 
líticas monetarias, cambiarias y fiscales, además de normas laborales, ambientales, providenciarías, regulación de capital, protección a los inversionistas y regulación de la competencia. Entre los principales ejemplos están el Mercado Común de América Central (MCCA) y el Mercado Común de países del Caribe (Caricom).

Asimismo, de acuerdo con Baumann, Canuto y Gonçalves (2004) y Balassa (1964), el próximo nivel superior después de un Mercado Común y Unión Monetaria sería la unión económica total. ${ }^{3}$ Además de todas las características anteriores de modalidades de integración ésta puede establecerse por instituciones supranacionales con autoridad sobre todos los estados miembros, en que se presupone la unificación de políticas sociales y anti-cíclicas, donde se constituyen políticas de forma homogénea entre los estados miembros.

El último nivel seria la Unión Política o fusión de los Estados Nacionales en un único Estado Nuevo cuyas decisiones deben obedecerse con carácter obligatorio. Como señalan Baumann, Canuto y Gonçalves (2004), los mejores ejemplos son los procesos de unificación de Italia y de Alemania que sucedieron en la mitad del siglo XIX.

Por último, Viner (1950) realizó un estudio sobre las consecuencias para el bienestar de los acuerdos comerciales regionales como lo fue la creación de un mercado común europeo. En este análisis, Viner (1950) que es contemporáneo a la época de la propuesta del second best ${ }^{4}$ no concordaba con la posición convencional de los economistas que se basan en la teoría de la ventaja comparativa, como la mayor eficiencia en la asignación de recursos como consecuencia de la mayor competencia en el aumento de los flujos de factores entre los miembros.

\section{Estimación Índice de Integración Institucional del MCCA}

El Índice de Integración de Institucional de Dorrucci et al. (2002) es construido fundamentalmente en base a las formas y grados de integración económica de Balassa (1964) siguiendo la jerarquía instrumentos jurídicos de la Teoría de las Re-

3 Un tema de interés recurrente entre los economistas del mainstream consiste en la teoría de un área monetaria óptima (AMO), donde se especifican las condiciones necesarias y suficientes para la creación de una moneda común dentro de una región económica. Dentro de estas condiciones estarían flexibilidad de precios y salarios, movilidad del factor trabajo y capital, y política fiscal coordinada con la política monetaria. Mundell (1961) propone la creación de AMO como una etapa final de un proceso de integración económica regional.

$4 \quad$ El teorema establece que si una de las condiciones necesarias para alcanzar un Óptimo de Pareto no es obtenible, las otras, a pesar de ser teóricamente posibles, dejan de ser deseables. En otras palabras, si una de las condiciones para alcanzar el óptimo de Pareto no es alcanzable, solo es posible conseguir un óptimo abandonando las otras condiciones. El óptimo así alcanzado solo puede ser llamado del Segundo Mejor porque está sujeto a una restricción que, por su definición, provee el alcance de un óptimo de Pareto (LIPSEY; LANCASTER, 1956). 
laciones Internacionales de Castro (2012) ${ }^{5}$ y Secretaria de Integración Económica Centroaméricana et al. (2010) que divide la historia del MCCA.

Para la construcción del Índice de Integración Institucional se consideró el criterio metodológico de otorgar en la puntuación una importancia o un mayor peso porcentual a los tratados comerciales firmados (30\%), los acuerdos comerciales $(25 \%)$, convenios $(20 \%)$ y un menor a los protocolos (10\%), carta constitutiva (10\%) y códigos (5\%) a los que sumados todos totalizan 100\% de acuerdo a Dorrucci et al. (2002). La razón de aplicar esta metodología de asignar diferentes pesos porcentuales a estos instrumentos jurídicos es debido que el enorme efecto político en cuanto a medios de comunicación, sectores empresariales y sindicales y ambientes académicos del anuncio oficial de la firma de un Tratado de Libre Comercio ya que crea señales de la dirección y vinculación de la política comercial externa de los países involucrados.

La ponderación del $25 \%$ de cada fase de Balassa (1964) corresponde a la clasificación realizada por Secretaria de Integración Económica Centroaméricana et al. (2010) para el caso específico del proceso de integración del MCCA, donde a su vez comprende también a las dos modelos de desarrollo económico (substitución de importaciones e inserción de la economía internacional).

En la Tabla 1 se muestran los cuatro grados o las cuatro fases de integración económica como fue definida por Balassa (1964). La puntuación (the score) fue obtenida después de calcular la sumatoria de cada uno de los acuerdos, convenios, protocolos, cartas y códigos alcanzados en función de cada etapa de integración económica y su construcción se presenta de forma detallada en el Cuadro 2 del Apéndice.

Por otra parte, vale la pena resaltar que la integración económica de América Central es un caso particular sui generis, ya que el tratado constitutivo de 1960 señala todas las fases como objetivos indispensables para consolidar la unión económica centroamericana, pero no impone restricciones de carácter obligatorio para completar una fase de integración consolidada plenamente como un prerrequisito previo para poder aspirar a completar la siguiente etapa. A este fenómeno se le denomina en la literatura de integración económica como la Geometría Variable el que cual fue adaptado de Funes (2011) por Orellana Aragón (s2015).

El índice fue construido utilizando como fundamento a arquitectura institucional integracionista económica que ha sido sustentada durante los últimos 60 años en Acuerdos, Protocolos y Convenios tan importantes como lo fueron: El

5 Castro (2012) utiliza una praxeología que define las alianzas, coaliciones, distanciamientos y rupturas entre los países. Partiendo de este marco conceptual los autores de este artículo para construir el índice jerarquizan los instrumentos jurídicos que posean mayor alcance y profundidad de una política comercial y que favorezcan la integración económica internacional asignándole un peso porcentual mayor a menor en este orden: 1) tratados comerciales; 2) acuerdos comerciales; 3) convenios; 4) protocolos; 5) carta constitutiva; y 6) códigos. 
Protocolo de Tegucigalpa a la carta de la Organización de Estados Centroamericanos (ODECA), Los Protocolos al Tratado General de Integración Económica Centroamericana (Protocolo de Guatemala de 1960 y Managua de 1962), el Convenio sobre el Régimen de Industrias Centroamericanas de Integración. (1958), Convenio sobre el régimen arancelario y aduanero centroamericano de 1997.y el Acuerdo de Asociación entre el Sistema de la Integración Centroamericana y la Republica Dominicana (2003).

Tabla 1 - Índice de Integración Institucional del MCCA, Unión Europea y Mercosur

\begin{tabular}{l|c|c|c|c|c}
\hline $\begin{array}{l}\text { Fase de Integración } \\
\text { Económica }\end{array}$ & Sigla & Puntos & MCCA & UE & Mercosur \\
\hline Zona de Libre Comercio & (ZLC) & 25 & 20.04 & 25 & 10 \\
Unión Aduanera & (UA) & 25 & 24.92 & 25 & 8 \\
Mercado Común & (MC) & 25 & 24.24 & 25 & 6 \\
Unión Económica Total & (UET) & 25 & 0 & 11 & 0 \\
\hline \multicolumn{2}{l|}{ Total } & $\mathbf{1 0 0}$ & $\mathbf{6 9 . 2}$ & $\mathbf{8 6}$ & $\mathbf{2 4}$ \\
\hline
\end{tabular}

Fuente: Construcción propia a excepción de los casos UE y Mercosur donde los cálculos fueron realizados por Dorrucci et al. (2002).

Como puede observarse en el Gráfico 2, el mayor salto que se registró en el índice de integración institucional económica para MCCA fue el experimentado en la década de los años cincuenta como bien lo dice Guerra-Borges (1975) y guarda alguna correlación con el UE ya en el caso Mercosur sucede a partir del año 1991 y muestra un mayor rezago que los otros países del bloque tales como Paraguay y Uruguay.

Esto es debido a la numerosa cantidad de acuerdos, convenios, protocolos y especialmente la carta inicial de la ODECA (1951) que dio un sustento legal para todo lo alcanzado posteriormente. Por eso la década de los años cincuenta fue fundamental para consolidar el proceso de integración económica.

Posteriormente durante la década de los años sesenta el índice no registró un aumento significativo. Esto puede percibirse debido a la abundante legislación y acuerdos alcanzados e implementados en la década de los años sesenta. Posteriormente, en la década de los años ochenta, el proceso observó que a causa de los retrocesos registrados debido a la crisis económica a principios de los años ochenta, dio lugar a que se organizaran diversas iniciativas para relanzar el proceso de integración económica y otros procesos políticos de negociación para alcanzar la paz en los conflictos armados en El Salvador, Guatemala y Nicaragua. 
Gráfico 1 - Índice de Integración Institucional del MCCA, UE y Mercosur

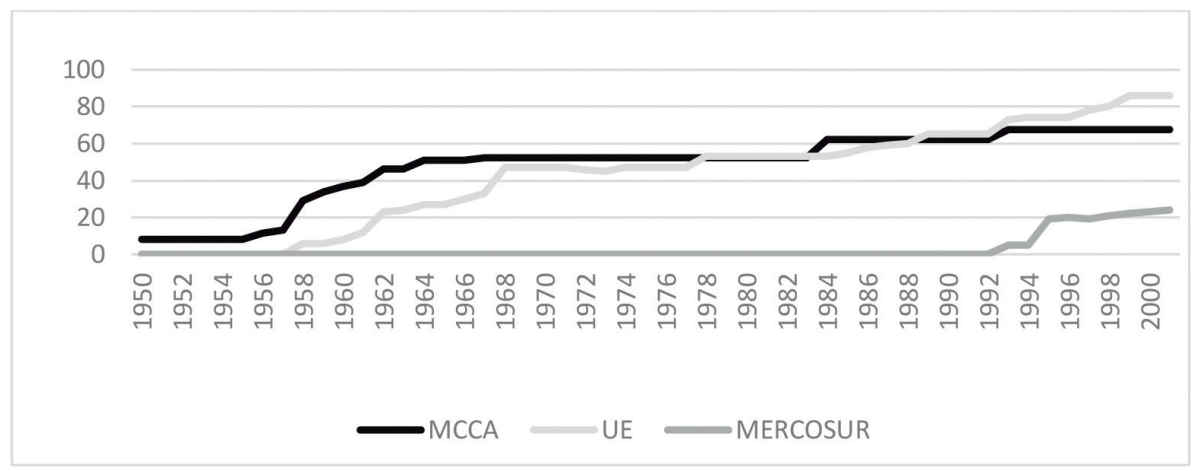

Fuente: Construcción propia y para el caso de la UE y Mercosur la estimación fue realizada por Dorrucci et al. (2002).

Cuando se comparan los resultados del trabajo realizado por Dorrucci et al. (2002), para la Unión Europea en la fase Zona de libre Comercio el mismo obtuvo 25 puntos, a continuación, en el caso de la Unión Aduanera arrojó un resultado de 25 puntos, en el caso de Mercado Común el resultado fue de también 25 puntos y finalmente Unión Económica Total el resultado fue de 12 puntos con los cuales totalizaron una sumatoria de 87 puntos. Por último, mucho más abajo se encuentra el Mercosur.

Con respecto a los puntajes alcanzados en el Índice de Integración en cada fase que se muestran detalladamente en el Cuadro 2 del Apéndice son los siguientes: Zona Libre Comercio (20.04), Unión Aduanera (24.92) y Mercado Común (24.24) y que totalizan 69.64 sobre un total de 100, donde puede evidenciarse claramente el avance alcanzado en el caso claramente de la unión aduanera y el arancel externo común obtenido entre El Salvador y Guatemala, gracias a la voluntad política de hacer todo el esfuerzo por agilizar e implementar de forma operativa la legislación que existía desde 1960 y de los acuerdos alcanzados en el año 2001.

\section{Hechos Estilizados de algunas Variables de MCCA-RD}

Como una derivación del Índice de Integración Institucional y Económica, de Dorrucci et al. (2004), se formuló un modelo de Vectores Autorregresivo (VAR). Para tal efecto se consideraron las siguientes variables: Índice Institucional de Integración Económica, Intensidad de la Apertura Comercial, Ingreso Per-Cápita por habitante del MCCA y Términos de Intercambio del MCCA.

Considerando una descripción del comportamiento de dichas variables desde la entrada en vigencia del Tratado en 1960, puede apreciarse en la Gráfica 3 
claramente en primer lugar, que el MCCA está experimentando una intensa apertura comercial ralentizada durante la década de los años ochenta, pero intensificada de forma decisiva en la década de los años noventa como parte de la estrategia de inserción de los países al comercio global por medio de la firma de acuerdos comerciales y la reducción de las barreras arancelarias y no arancelarias.

Gráfica 2 - Promedio de la Intensidad de la Apertura Comercial del MCCA

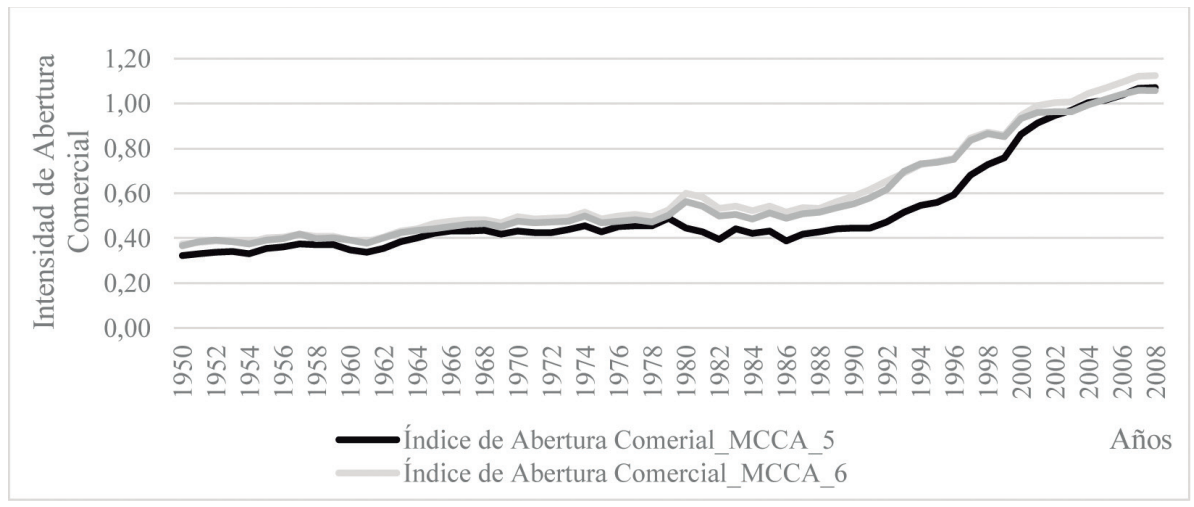

Fuente: Adaptado a partir de los datos de Comisión Económica para América Latina y el Caribe (2009) a precios constantes en el año base 2000.

A partir de la entrada en vigencia del MCCA puede observarse la mejora visible del ingreso per-cápita de los habitantes de la región centroamericana en la Gráfica 4. Durante la llamada época de oro registrada en los años sesenta y comienzos de los setenta con el aumento del poder adquisitivo se propició un aumento significativo en la construcción de proyectos habitacionales. Posteriormente en la década de los años ochenta, el ingreso per cápita tuvo una severa caída derivada de la llamada "crisis de la deuda". No fue sino apenas a principios de los años noventa que la región retoma y recupera el crecimiento y los niveles alcanzados en la década de los años setenta como lo muestra la Gráfica 3. 
Gráfica 3-Promedio ponderado del Ingreso Per- Cápita del MCCA

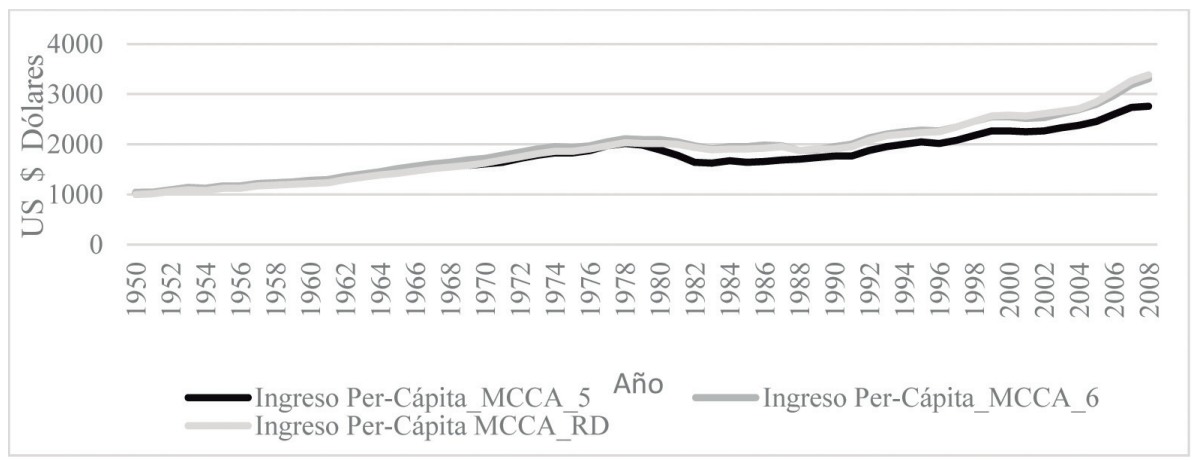

Fuente: Adaptado a partir de los datos de Comisión Económica para América Latina y el Caribe (2009) a precios constantes en el año base 2000.

Como puede observarse en la Gráfica 4, los términos del intercambio comercial para el MCCA tienen una tendencia a la baja luego de una leve tendencia al alta a mediados de los años noventa. Esta tendencia aparentemente no mejoró, inclusive considerando el boom favorable que experimentaron y sufrieron los precios de los principales productos commodities de exportación, por lo que evidentemente, esta circunstancia no se reflejó en los últimos años.

Gráfica 4 - Promedio Ponderado de los Términos de Intercambio Comercial del MCCA

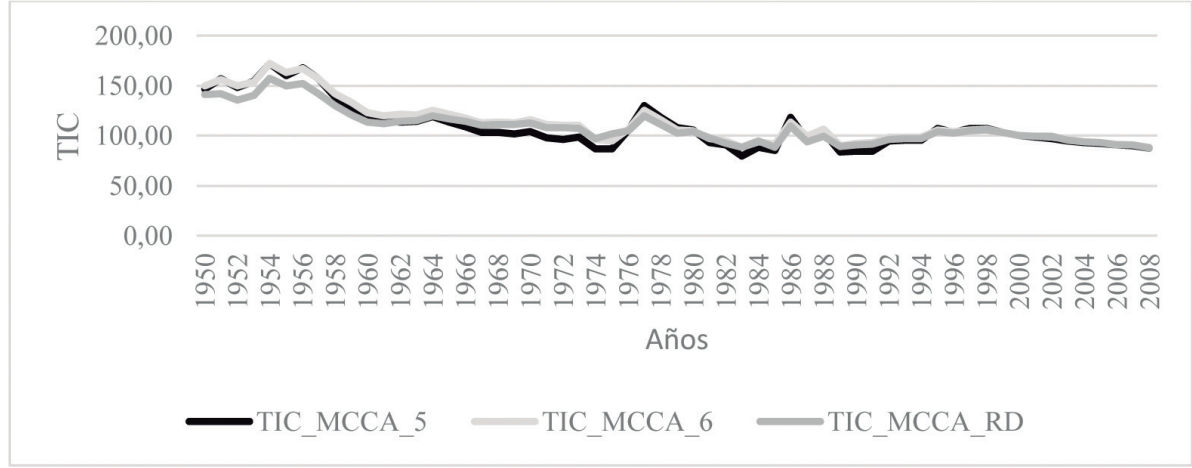

Fuente: Adaptado a partir de los datos de Comisión Económica para América Latina y el Caribe (2009) a precios constantes en el año base 2000.

\subsection{Estimación del Modelo}

En total se realizaron tres aplicaciones para el modelo VAR. La primera involucra a los siguientes países del MCCA: Costa Rica, El Salvador, Guatemala, Honduras y Nicaragua expresado con la sigla MCCA_5. En la segunda prueba se incor- 
pora Panamá a todos los demás y se muestra con la sigla MCCA_6 y por último en la tercera, se agrega la República Dominicana expresado con la sigla MCCA_RD. Las variables endógenas se describen en el Cuadro 1 donde aparecen respectivamente con su sigla, descripción y fuente.

Cuadro 1 - Variables utilizadas, descripción y fuente

\begin{tabular}{|c|c|c|c|}
\hline Variable & Sigla & Descripción & Fuente \\
\hline $\begin{array}{l}\text { Índice } \\
\text { Institucional } \\
\text { de } \\
\text { Integración } \\
\text { Económica }\end{array}$ & $\begin{array}{c}\text { L_INDEX_ }_{\text {INT }} \\
\text { MCCA }\end{array}$ & $\begin{array}{l}\text { Logaritmo del índice cons- } \\
\text { truido en base a los Tratados, } \\
\text { Acuerdos, Convenios, Protoco- } \\
\text { los y Cartas que han llevado a } \\
\text { consolidar las diferentes fases o } \\
\text { etapas de integración (Zona de } \\
\text { Libre Comercio, Unión Adua- } \\
\text { nera, Mercado Común y Unión } \\
\text { Económica Total) del MCCA y } \\
\text { expresado en forma anual. }\end{array}$ & $\begin{array}{c}\text { Secretaría de } \\
\text { Integración } \\
\text { Económica } \\
\text { Centroamericana } \\
\text { (SIECA) }\end{array}$ \\
\hline $\begin{array}{l}\text { Intensidad } \\
\text { de la } \\
\text { Apertura } \\
\text { Comercial }\end{array}$ & $\begin{array}{l}\mathrm{L}_{\mathbf{M}}^{\mathrm{TIO}} \\
\overline{\mathrm{M} C \mathrm{~A}}\end{array}$ & $\begin{array}{l}\text { Logaritmo del promedio anual } \\
\text { del cociente de la sumatoria } \\
\text { de las exportaciones e Impor- } \\
\text { taciones de Bienes y Servicios } \\
\text { en relación al Producto Interno } \\
\text { Bruto expresado en precios } \\
\text { constantes del año } 2000 .\end{array}$ & $\begin{array}{l}\text { Estadísticas Eco- } \\
\text { nómicas de la } \\
\text { Comisión Econó- } \\
\text { mica de América } \\
\text { Latina y el Caribe } \\
\text { (Cepal) }\end{array}$ \\
\hline $\begin{array}{l}\text { Ingreso Per- } \\
\text { Cápita por } \\
\text { habitante de } \\
\text { MCCA }\end{array}$ & 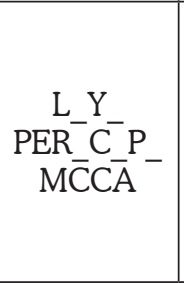 & $\begin{array}{l}\text { Logaritmo del promedio pon- } \\
\text { derado del Ingreso per-cápita } \\
\text { considerando el tamaño de la } \\
\text { economía (PIB) de cada uno } \\
\text { de los estados miembros del } \\
\text { MCCA a precios constantes del } \\
\text { año } 2000\end{array}$ & $\begin{array}{c}\text { Estadísticas } \\
\text { Económicas } \\
\text { de la Comisión } \\
\text { Económica de } \\
\text { América Latina y } \\
\text { el Caribe (Cepal) }\end{array}$ \\
\hline $\begin{array}{l}\text { Términos de } \\
\text { Intercambio } \\
\text { del MCCA }\end{array}$ & $\begin{array}{l}\text { L_TIC } \\
\text { PONND } \\
\text { MCCA }^{-}\end{array}$ & $\begin{array}{l}\text { Logaritmo del promedio pon- } \\
\text { derado de los términos de } \\
\text { intercambio considerando la } \\
\text { intensidad de comercio de } \\
\text { cada uno de los miembros del } \\
\text { MCCA a precios constantes del } \\
\text { año } 2000 \text {. }\end{array}$ & $\begin{array}{c}\text { Estadísticas } \\
\text { Económicas } \\
\text { de la Comisión } \\
\text { Económica de } \\
\text { América Latina y } \\
\text { el Caribe (Cepal) }\end{array}$ \\
\hline
\end{tabular}

Fuente: Elaboración propia a partir de Comisión Económica para América Latina Y el Caribe (2009) y de Secretaria de Integración Económica Centroaméricana (2015).

En primer lugar, se realizó la Prueba Dickey Fuller Aumentada (ADF) para identificar si las variables eran estacionarias. Allí se muestran las tres pruebas de VAR. Los resultados se presentan a continuación en la Tabla 3. De acuerdo a los re- 
sultados de la prueba ADF constante y tendencia, la variable LINDEX_INT_MCCA no necesitó ninguna diferencia siendo estacionaria en nivel. En cambio, en los casos las variables LTIO_MCCA, LY_P_MCCA y LTIC_POND_MCCA no eran estacionarias en nivel y fue necesario aplicar la primera diferencia en las tres pruebas aplicadas para los grupos de países miembros del MCCA. Para tal efecto las variables fueron, renombradas DLTIO_MCCA, DLY_P_C_MCCA y DLTIC_POND_MCCA. Después del tratamiento de las variables el modelo quedó de la siguiente forma:

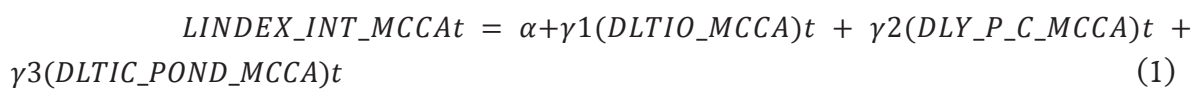

En cuanto a la elección de regazos óptimo, el mejor modelo para las tres pruebas fue el de un rezago o retardo de acuerdo a los criterios del Akaike Information Criterion (AIC) y Schwartz Criterion (SC) mostrados en la Tabla 2.

Tabla 2 - Criterio de Elección de retardo óptimo

\begin{tabular}{cccc}
\hline Bloque & Lag & AIC & SC \\
\hline MCCA_5 & 1 & $-11.82677^{*}$ & $-11.08326^{*}$ \\
MCCA_6 & 1 & $-12.85745^{*}$ & $-12.11395^{*}$ \\
MCCA_RD & 1 & $-13.46057^{*}$ & $-12.71707^{*}$ \\
\hline
\end{tabular}

Fuente: Adaptado a partir de datos de Comisión Económica para América Latina Y el Caribe (2009).

Para encontrar la estructura del retardo o rezago se calculó la tabla de raíces unitarias, es decir, las raíces del polinomio característico, donde todos los resultados de los eigenvalores fueron menores que la unidad, es decir, caen en el círculo unitario. Por esta razón se dice que el sistema es estable y estacionario como se muestra en la Figura 1. Posteriormente, cuando fue revisada la raíz inversa del polinomio autorregresivo del VAR se pudo visualizar la estabilidad del modelo estimado el cual se presenta en la Figura 5. En la representación gráfica de los eingenvalores se muestra que todos los valores se encuentran dentro del círculo unitario. En consecuencia, indica que existe una tendencia común por lo que se puede esperar la existencia de un vector de cointegración. 
Figura 1- Test de estabilidad del VAR

a) MCCA_5

Inverse Roots of AR Characteristic Polynomial

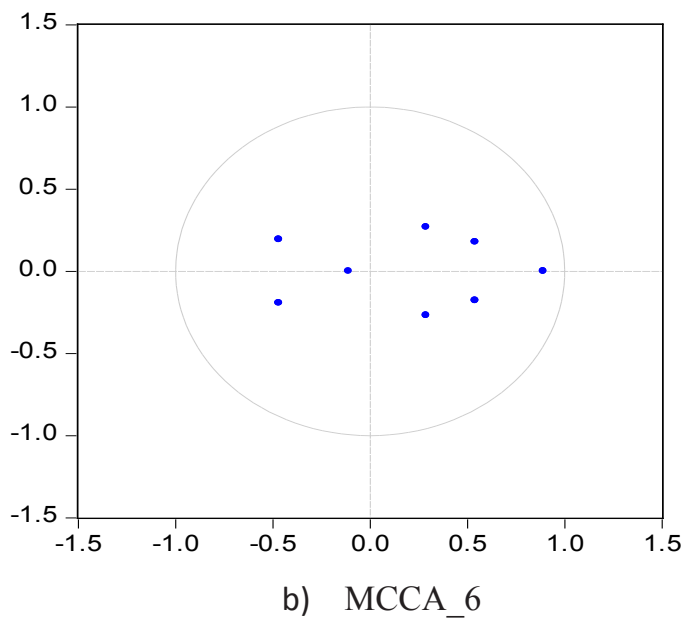

Inverse Roots of AR Characteristic Polynomial

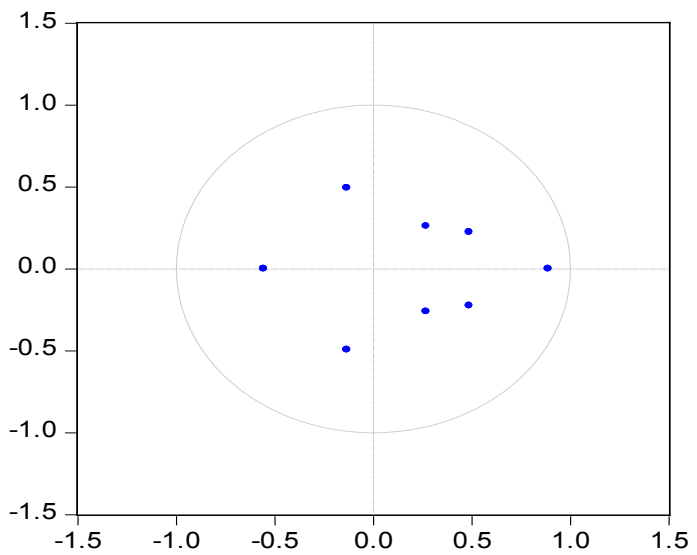


c) MCCA_RD

Inverse Roots of AR Characteristic Polynomial

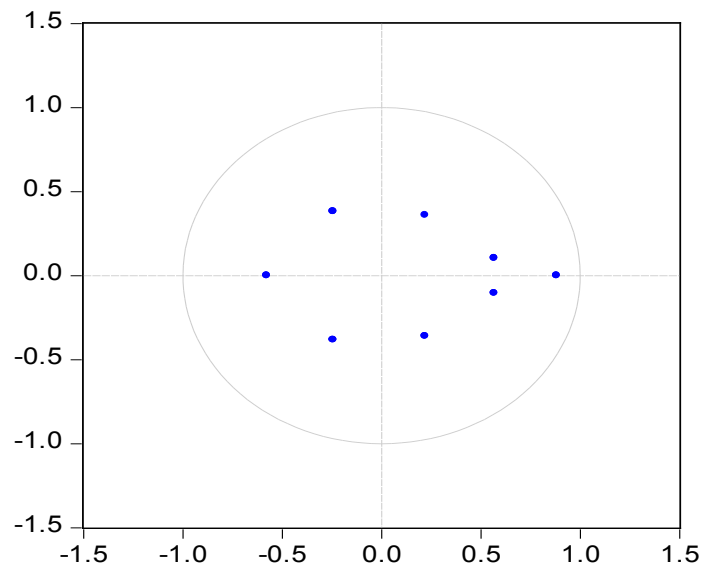

Fuente: Adaptado a partir de datos de Comisión Económica para América Latina Y el Caribe (2009).

El siguiente paso fue obtener las funciones impulso-respuesta para verificar la respuesta de una determinada variable en relación a un shock o un impulso dado. De hecho, a un incremento equivalente a una desviación estándar en el valor corriente de uno de los errores del VAR, asumiendo que el error retorna a cero en el siguiente período y que el resto de errores son iguales a cero. Para este VAR se consideran en el futuro 10 períodos anuales y se muestran los resultados en el Apéndice A, Gráfica 5.

Para el caso del MCCA_5 un aumento sorpresivo de una desviación estándar en el índice de integración debería provocar un aumento positivo en la apertura comercial en los primeros períodos y el efecto se disipa en el noveno período. Por otra parte, un aumento inesperado en el índice de integración correspondería provocar un aumento de los términos de intercambio comercial en los primeros períodos y a que después de 9 periodos gradualmente llega a ser 0 . En la segunda prueba del MCCA_6 los resultados son bastantes similares para el caso del índice de integración sobre la apertura comercial y los términos de intercambio. Y finalmente en el caso del MCCA_RD el efecto es positivo hasta los 10 años del índice de integración sobre la apertura comercial y es negativo al principio en los términos de intercambio comercial en los primeros tres períodos, hasta llegar a estabilizarse en el noveno período.

Para el análisis de descomposición de varianza se consideraron 10 períodos anuales y los resultados se muestran comenzando con la primera prueba del MCCA_5 para el tercer periodo en el corto plazo, donde un impulso, shock, in- 
novaciones de la apertura comercial puede causar fluctuaciones en el índice de integración institucional en el orden del 2.08\%. En el caso de ingreso per-cápita, ocasiona una fluctuación de $0.63 \%$ y por último para los términos de intercambio produce $0.62 \%$. Ya en el largo plazo del periodo 10 una innovación en la apertura comercial ocasionará una fluctuación del 1,57\% y por su parte un shock del ingreso per-cápita causará una fluctuación del orden del 6.75\%. Por último, un impulso de los términos de intercambio puede provocar una fluctuación del $0.61 \%$ en el índice de integración.

Para el análisis de descomposición de varianza se consideraron 10 períodos anuales y los resultados se muestran comenzando con la primera prueba del MCCA_5 para el tercer periodo en el corto plazo, donde un impulso, shock, innovaciones de la apertura comercial puede causar fluctuaciones en el índice de integración institucional en el orden del 2.08\%. En el caso de ingreso per-cápita, ocasiona una fluctuación de $0.63 \%$ y por último para los términos de intercambio produce $0.62 \%$. Ya en el largo plazo del periodo 10 una innovación en la apertura comercial ocasionará una fluctuación del 1,57\% y por su parte un shock del ingreso per-cápita causará una fluctuación del orden del $6.75 \%$. Por último, un impulso de los términos de intercambio puede provocar una fluctuación del $0.61 \%$ en el índice de integración.

En la prueba del MCCA_6 el índice de integración experimentará fluctuaciones recibidas de las innovaciones en los casos de la apertura comercial (0.66\%), ingreso per cápita (2.73\%) y términos de intercambio comercial (1.72\%). Y finalmente, en el caso del MCCA_RD registrará fluctuaciones recibidas de las innovaciones en el décimo año en los casos de la apertura comercial (1.92\%), ingreso per cápita (2.69\%) y en los términos de intercambio comercial (2.78\%).

La prueba de heterocedasticidad de término sin cruzados de White sirve para validar uno de los supuestos del modelo de Regresión Lineal en que todos los términos de error tienen la misma varianza, para tal efecto los resultados se muestran en la Tabla A.8. Como la probabilidad conjunta de cada una de las tres pruebas $(0.2793>0.05,0.1011>0.05$ y $0.3617>0.05)$, es mayor que $0.05 \%$ por lo que los residuos son homocedásticos. 
Tabla 3 - Prueba Dickey Fuller Aumentada (ADF)

\begin{tabular}{|c|c|c|c|c|}
\hline Bloque & Variables & $\mathrm{T} / \mathrm{C}$ & ADF & P-valor \\
\hline \multirow{2}{*}{ 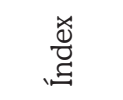 } & L_INDEX_INT_MCCA & c & -3.1313 & 0.0297 \\
\hline & DL_INDEX_INT_MCCA & $\mathrm{ct}$ & -3.5672 & 0.0423 \\
\hline \multirow{12}{*}{ 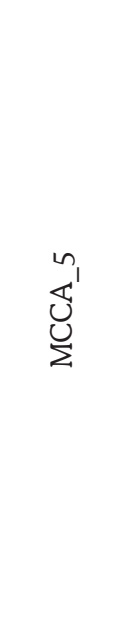 } & L_TIO_MCCA_5 & c & 1.2607 & 0.9982 \\
\hline & L_TIO_MCCA_5 & $\mathrm{ct}$ & -0.4892 & 0.9814 \\
\hline & L_Y_PER_C_P_MCCA_5 & c & -0.8494 & 0.7970 \\
\hline & L_Y_PER_C_P_MCCA_5 & $\mathrm{ct}$ & -2.1910 & 0.4852 \\
\hline & L_TIC_POND_MCCA_5 & c & -2.0710 & 0.2569 \\
\hline & L_TIC_POND_MCCA_5 & $\mathrm{ct}$ & -3.0335 & 0.1326 \\
\hline & DL_TIO_MCCA_5 & c & -7.0610 & 0.0000 \\
\hline & DL_TIO_MCCA_5 & $\mathrm{ct}$ & -7.4251 & 0.0000 \\
\hline & DL_Y_PER_C_P_MCCA_5 & c & -4.1874 & 0.0016 \\
\hline & DL_Y_PER_C_P_MCCA_5 & $\mathrm{ct}$ & -4.1499 & 0.0094 \\
\hline & DL_TIC_POND_MCCA_5 & c & -5.2553 & 0.0001 \\
\hline & DL_TIC_POND_MCCA_5 & $\mathrm{ct}$ & -5.2623 & 0.0003 \\
\hline \multirow{12}{*}{\begin{tabular}{l}
0 \\
$\mathbb{U}^{\prime}$ \\
\multirow{u}{\Sigma}{}
\end{tabular}} & L_TIO_MCCA_6 & c & 1.0234 & 0.9964 \\
\hline & L_TIO_MCCA_6 & $\mathrm{ct}$ & -1.2107 & 0.8988 \\
\hline & L_Y_PER_C_P_MCCA_6 & c & -0.4067 & 0.9006 \\
\hline & L_Y_PER_C_P_MCCA_6 & $\mathrm{ct}$ & -1.8786 & 0.6525 \\
\hline & L_TIC_POND_MCCA_6 & c & -1.6423 & 0.4549 \\
\hline & L_TIC_POND_MCCA_6 & $\mathrm{ct}$ & -2.6670 & 0.2538 \\
\hline & DL_TIO_MCCA_6 & c & -7.2282 & 0.0000 \\
\hline & DL_TIO_MCCA_6 & $\mathrm{ct}$ & -7.4752 & 0.0000 \\
\hline & DL_Y_PER_C_P_MCCA_6 & c & -4.2535 & 0.0013 \\
\hline & DL_Y_PER_C_P_MCCA_6 & $\mathrm{ct}$ & -4.2162 & 0.0078 \\
\hline & DL_TIC_POND_MCCA_6 & c & -5.5602 & 0.0000 \\
\hline & DL_TIC_POND_MCCA_6 & $\mathrm{ct}$ & -5.5577 & 0.0001 \\
\hline
\end{tabular}




\begin{tabular}{|c|c|c|c|c|}
\hline Bloque & Variables & $\mathbf{T} / \mathbf{C}$ & ADF & P-valor \\
\hline \multirow{12}{*}{ 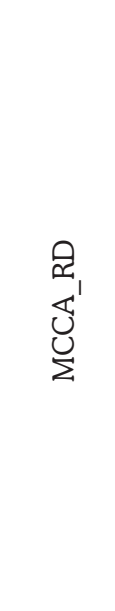 } & L_TIO_MCCA_7 & c & 0.8406 & 0.9940 \\
\hline & L TIO MCCA 7 & $\mathrm{ct}$ & -1.2083 & 0.8993 \\
\hline & L_Y_PER_C_P_MCCA_7 & c & -0.0105 & 0.9534 \\
\hline & L_Y_PER_C_P_MCCA_7 & $\mathrm{ct}$ & -1.6415 & 0.7638 \\
\hline & L_TIC_POND_MCCA_7 & c & -1.5826 & 0.4848 \\
\hline & L_TIC_POND_MCCA_7 & $\mathrm{ct}$ & -2.8192 & 0.1968 \\
\hline & DL_TIO_MCCA_7 & c & -7.1916 & 0.0000 \\
\hline & DL_TIO_MCCA_7 & $\mathrm{ct}$ & -7.4605 & 0.0000 \\
\hline & DL_Y_PER_C_P_MCCA_7 & c & -4.3551 & 0.0009 \\
\hline & DL_Y_PER_C_P_MCCA_7 & $\mathrm{ct}$ & -4.3360 & 0.0056 \\
\hline & DL_TIC_POND_MCCA_7 & c & -10.1381 & 0.0000 \\
\hline & DL TIC POND MCCA 7 & $\mathrm{ct}$ & -10.0713 & 0.0000 \\
\hline
\end{tabular}

Fuente: Adaptado a partir de datos de Comisión Económica para América Latina Y el Caribe (2009).

\section{Consideraciones Finales}

Cuando se observa el índice de integración institucional do MCCA estimado en este trabajo, que durante en el período de 1952, comparado a los cuatro años comprendidos entre 1958 e 1962, fue presentada mejor actividad preparatoria. Esto es claramente reflejado en el comportamiento del índice debido al aumento significativo durante este período. En este punto, es totalmente consistente con las opiniones expresadas por Guerra-Borges (1975), ya que fueron firmados cinco acuerdos claves durante este período, los cuales son el Tratado Multilateral sobre Libre Comercio e Integración Económica, el Acuerdo Centro-Americano de Ecualización de Evaluaciones para la importación (1960), el Tratado de Integración Económica (1962), el Convenio del BCIE (1960) y el Acuerdo Centro-Americano de Incentivos Fiscales para el Desarrollo industrial (1958). Se puede afirmar que existe una clara correlación directa entre la evolución en cuanto a la integración de bloque económico entre el MCCA y UE en esa etapa inicial

Por otro lado, la puntuación total del Índice de Integración Institucional del MCCA-RD obtiene un resultado de 69,2, que es la suma de las fases de la Área de Libre Comercio (20.04), Unión Aduanera (24.92), Mercado Común (24,24) y de la Unión Económica Total (0). Tanto en el caso da Unión Aduanera y el Mercado Común tuvo un buen resultado debido, en parte gracias a la sólida base que sustenta su arquitectura institucional e instrumentos como el Sistema Arancela- 
rio Centroamericano -SAC-, el Código Arancelario Centroamericano I, II, III e IV (CAUCA) y el Reglamento (RECAUCA) concretizada con base en acuerdos, tratados, convenciones e protocolos descritos ácima.

Por otra parte, como fue mencionado anteriormente, la puntuación del índice de integración para MCCA-RD fue de 69,2 e es significativamente menor en comparación con el resultado obtenido por Dorrucci et al. (2002), que era de 87 para a Unión Europea (UE) denotando una clara diferencia de 17,8 pontos, aunque mucho mayor que el obtenido para el caso del Mercosur que alcanza 24 lo cual puede explicarse por el poder limitado de las instituciones que fueron creadas para favorecer la integración a este bloque. El resultado es explicado en el MCCA-RD por el resultado de 0 en la fase de Unión Económica Total (UET). En contraste, la UE alcanzó un valor próximo de 12 pontos. Lo anterior puede explicar el predominio en varios países a mantener una pauta de exportación de productos industriales en el comercio intra-bloque tales como sucede en el Mercosur con Brasil y en menor grado Argentina en contraste con Paraguay y Uruguay países volcados a la exportación de productos agrícolas y primarios.

Estos problemas crónicos asimetrías son ampliamente repetidos en el MCCA$-\mathrm{RD}$ con Nicaragua y Honduras con productos de bajo valor agregado y en la UE con España, Grecia y Portugal frente a países como Alemania, Francia e Italia.

Por último, cuando es comparado el modelo empírico VAR obtenido por Dorrucci et al. (2004), en el presente estudio debe ser considerado que no fueron utilizados exactamente las mismas variables y frecuencia de la serie. Nótese que, por el contrario, en este trabajo fueron utilizadas variables de proxy como la media ponderada de los términos de intercambio comercial para substituir la tasa de cambio real, media ponderada de la renta per cápita y el índice de apertura do comercio, todos expresados en una base anual para el período 1950 a 2008. En cuanto, en el modelo VAR, Dorrucci et al. (2004) muestran un choque sorpresivo (no anticipado) de la liberalización de comercio que tiene un efecto muy positivo en los primeros seis períodos sobre el Índice de integración. En cambio, de los tres modelos VAR (MCCA, MCCA_6 e MCCA_RD) el efecto es negativo en los dos primeros períodos, pero después tiene un efecto ligeramente positivo. En contradicción con los resultados, para Dorrucci et al. (2004), el efecto de una innovación inesperada de la renta per cápita en el índice de integración institucional es muy negativa en los cuatro primeros períodos y permanece así hasta el período 15. A pesar de lo expuesto ácima en los tres modelos VAR propuestos, los efectos son ambiguos, o sea, positivo o negativo en las fases iniciales y más tarde acaba por ser ligeramente positivo.

Otros resultados del VAR para MCCA (5 países), MCCA_6 (5 países e Panamá) e MCCA_RD (6 países e República Dominicana) apuntan una causalidad en el sentido de Granger, la variación de LINDEX_INT puede ser explicado por 
la variación de la propia variable. En ambos casos del MCCA y MCCA_6 a renta per-cápita tiene un efecto sobre los términos de intercambio comercial. Además de eso, cuando son analizados los efectos de las funciones impulso y respuesta, fue descubierto que en los casos del MCCA y MCCA_6 un aumento no anticipado en el desvió padrón del Índice de Integración, causa un aumento positivo en un noveno período en la apertura comercial lo que se corroboran en el caso UE con Dorrucci et al. (2002) de los beneficios del desarrollo institucional sobre el comercio intra-bloque.

Por último, un aumento inesperado en el Índice de Integración tiene un mayor efecto en los términos de intercambio comercial en los períodos iniciales, el que es disipado en las fases finales. Aunque en el caso de MCCA_RD hay un efecto positivo de un período de 10 años, lo que por su vez tiene un efecto positivo sobre a apertura comercial o liberalización de comercio y un efecto ambiguo en el inicio de los términos de intercambio comercial y, finalmente, se muestra positivo en el décimo período.

\section{Referencias}

ACUERDO DE ASOCIACIÓN ENTRE EL SISTEMA DE LA INTEGRACIÓN CENTROAMERICANA Y LA REPUBLICA DOMINICANA. Santo Domingo de Guzmán, 10 dic. 2003. p. 1-7. Disponible en: <http://www.sice.oas.org/Trade/sica/PDF/AcSICADOM03. pdf $>$. Acceso en: 23 feb. 2015.

BALASSA, B. Teoria da integração económica. Tradução Maria Filipa Gonçalves e Maria Elsa Ferreira. Lisboa: Livraria Clássica Editora, 1964. (Coleção de Economia Moderna).

BANCO INTERAMERICANO DE DESARROLLO; COMISIÓN ECONÓMICA PARA AMÉRICA LATINA. La integración centroamericana y la institucionalidad. BID; CEPAL: México, D.F., feb. 1998. p. 10-283.

BAUMANN, R.; CANUTO, O.; GONÇALVES, R. Economia internacional. Teoria e experiência brasileira. Rio de Janeiro: Elsevier, 2004.

BULMER-THOMAS, V. La economía política de Centroamérica desde 1920. Guatemala: Biblioteca Básica de Historia de Guatemala, 2011.

CANDELTEY DEL POZO, P. El desarrollo económico de Centroamérica en el Marco de la Integración Regional. Tegucigalpa: Banco Centroamericano de Integración Económica, 2000. p. 133-663. Disponible en: <http://www.fundacionetea.org/Media/File/Tesis_P Caldentey/Libro_Pedro_Caldentey.pdf $>$. Acceso en: 11 ago. 2013.

CASTRO, T. Teoria das relaçõés internacionais. Brasilia, DF: Fundação Alexandre de Guzmão, 2012.

COMISIÓN ECONÓMICA PARA AMÉRICA LATINA Y EL CARIBE. América Latina y el Caribe: series históricas de estadísticas económicas 1950-2008. Cuadernos Económicos, 
Santiago de Chile, n. 37, 2009. Disponible en: <http://interwp.cepal.org/cuaderno_37/index. htm >. Acceso en: 12 nov. 2014

El regionalismo abierto en América Latina y el Caribe. La integración económica al servicio de la Transformación Productiva con Equidad. Santiago de Chile: Naciones Unidas; Cepal, sept. 1994. p. 12-13. Disponible en: < http://repositorio.cepal.org/bitstream/ handle/11362/2140/S9481108_es.pdf?sequence=1 >. Acceso en: 26 ago. 2015.

CONVENIO sobre el Régimen Arancelario Y Aduanero Centroamericano. Guatemala, p. 1-20, julio 1997. Disponible en: <http://www.sice.oas.org/Trade/sica/PDF/Convenio84.pdf>. Acceso en: 15 jul. 2014.

CONVENIO sobre el Régimen de Industrias Centroamericanas de Integración. Tegucigalpa, 10 junio 1958. Disponible en: <http://www.sica.int/busqueda/busquedaarchivo.aspx?Archiv o=conv_1001_6_14062005.htm >. Acceso en: 4 oct. 2014.

DORRUCCI, E. et al. European Integration: what lessons for other regions? The Case of Latin America. Frankfurt: European Central Bank, Oct. 2002. p. 36-41. (European Central Bank Working Paper, n. 185). Disponible en: <http://www.suomen pankki.fi/pdf/105794.pdf>. Acceso en: 12 enero 2015.

DORRUCCI, E. et al. The link between institutional and economic integration: insights for Latin America from the European experience. Open Economic Review, Amsterdam, n. 15, p. 239-260, 2004. Disponible en: <http://link.springer.com/article/10.1023/ B\%3AOPEN.0000037699.34047.be> . Acceso en: 12 enero 2015.

FARIA, L. A. E.; FIORI, D. O comércio e o principio de equilíbrio no Mercosul: uma analise setorial. Indicadores Econômicos FEE, v. 38, n. 4, p. 81-94, 2011. Disponible en: < http:// revistas.fee.tche.br/index.php/indicadores/article/view/2513>. Acceso en: 11 feb. 2015.

FUNES, O. Retos de la Unión Aduanera en Centroamérica. México D.F.: Cepal, oct. 2011. p. 5-18. (Series de Estudios y Perspectivas, n. 131). Disponible en: < http://www10.iadb.org/ intal/intalcdi/PE/2011/09234.pdf>. Acceso en: 12 feb. 2015.

GILPIN, R. Global political economy: understanding the international economic order. Princeton: Princeton University Press, 2001.

GUERRA-BORGES. A. Ensayos sobre integración económica. Guatemala: Editorial Universitaria, 1975. v. 18. (Colección Aula).

LIPSEY, R. G.; LANCASTER, K. The general theory of the second best. Review of Economic Studies, Oxford, v. 24, n. 1, p. 11-32, 1956.

MUNDELL, R.A. A theory of optimum areas. American Economic Review, Pittsburg. v. 51, n. 4, p. 657-665, 9 Sept. 1961. Disponible en: <https:/www.aeaweb.org/aer/top20/51.4.657665.pdf>. Acceso en: 4 oct. 2014.

NORTH, D. C. Institutions, institutional change and economic performance. Cambridge: Cambridge University Press, 1990.

ORELLANA ARAGÓN, J. A. Ensaios economia internacional e integração: caso do Mercado Comum da América Central (MCCA). Tese (Doutorado em Economia) - Programa de Pós- 
Graduação em Economia, Faculdade de Ciências Econômicas, Universidade Federal de Rio Grande do Sul, Porto Alegre, 2015.

PROTOCOLO AL TRATADO GENERAL DE INTEGRACIÓN ECONÓMICA CENTROAMERICANA (Protocolo de Guatemala) Guatemala. p. 1-22, 1993. Disponible en: < http://www.sice.oas.org/Trade/sica/PDF/Prot.Guatemala93.pdf>. Acceso en: 10 enero 2015.

. Managua, p. 1-4, 1962. Disponible en: < http://www.sice.oas.org/Trade/sica/PDF/ ProtTraGral62.pdf>. Acceso en: 12 enero 2015.

PROTOCOLO DE TEGUCIGALPA A LA CARTA DE LA ORGANIZACIÓN DE ESTADOS CENTROAMERICANOS (ODECA). Tegucigalpa. p. 1-20, 1962. Disponible en: < http://www. sice.oas.org/trade/sica/SG121391.asp >. Acceso en : 12 feb. 2015.

SECRETARIA DE INTEGRACIÓN ECONÓMICA CENTROAMÉRICANA et al. El libro de referencia de la integración centroamericana: de la década 1951 al presente. Guatemala: Sieca, jun. 2010. p. 9-78. Disponible en: < http://www10.iadb.org/intal/intalcdi/ PE/2012/09778.pdf > . Acceso en: 23 jun. 2013

SECRETARIA DE INTEGRACIÓN ECONÓMICA CENTROAMÉRICANA. Sistema de Estadísticas de Comercio de Centroamérica. Guatemala: Sieca, 2015.

TREJOS DONALDSON, R. Apuntes sobre conceptos, balance y perspectivas de integración económica centroamericana. Secretaria Centroamericana de Integración Económica (SIECA), San José, p. 1-40, mar. 1997.

VINER, J. The customs union issue. New York: Carnegie Endowment for International Peace, 1950.

ZAPATA, R.; PÉREZ CALDENTEY, E. Pasado, presente y futuro del proceso de integración centroamericano-una interpretación. México, D.F.: Sede Subregional en México, 2005. p. 5-39. (Serie Estudios y Perspectivas, n. 6). 


\section{Apéndice $\mathrm{A}$}

Gráfica 5 - Funciones impulso-respuesta

a) MCCA_5

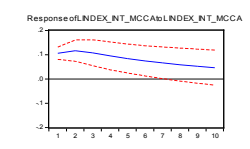

Responses 10 Chalesty One S.D. Innovatione \pm 2 SE.
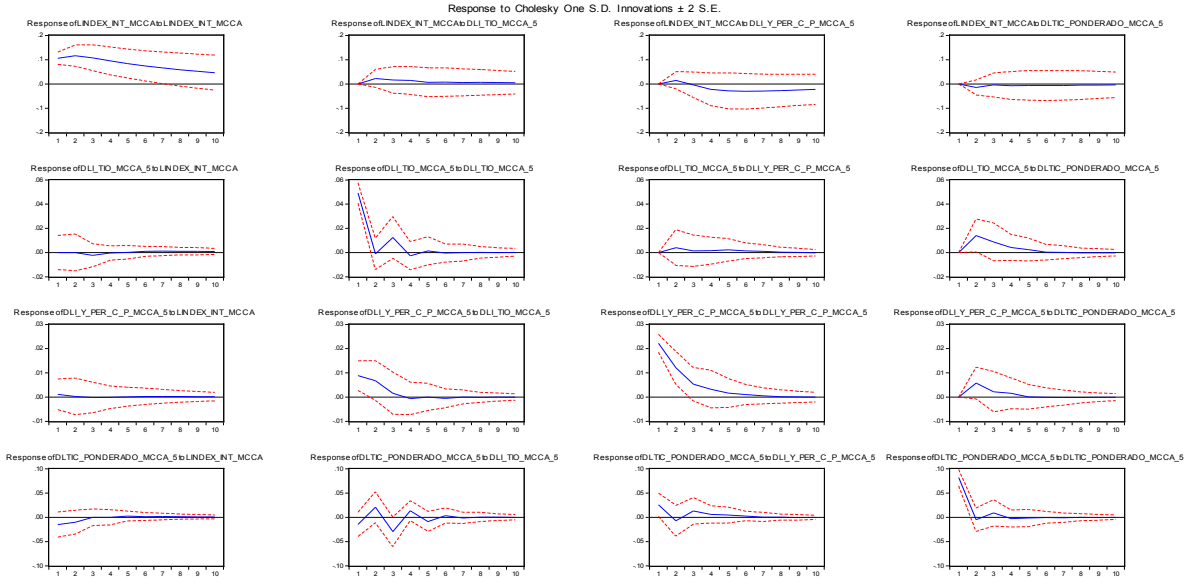

b) MCCA_6
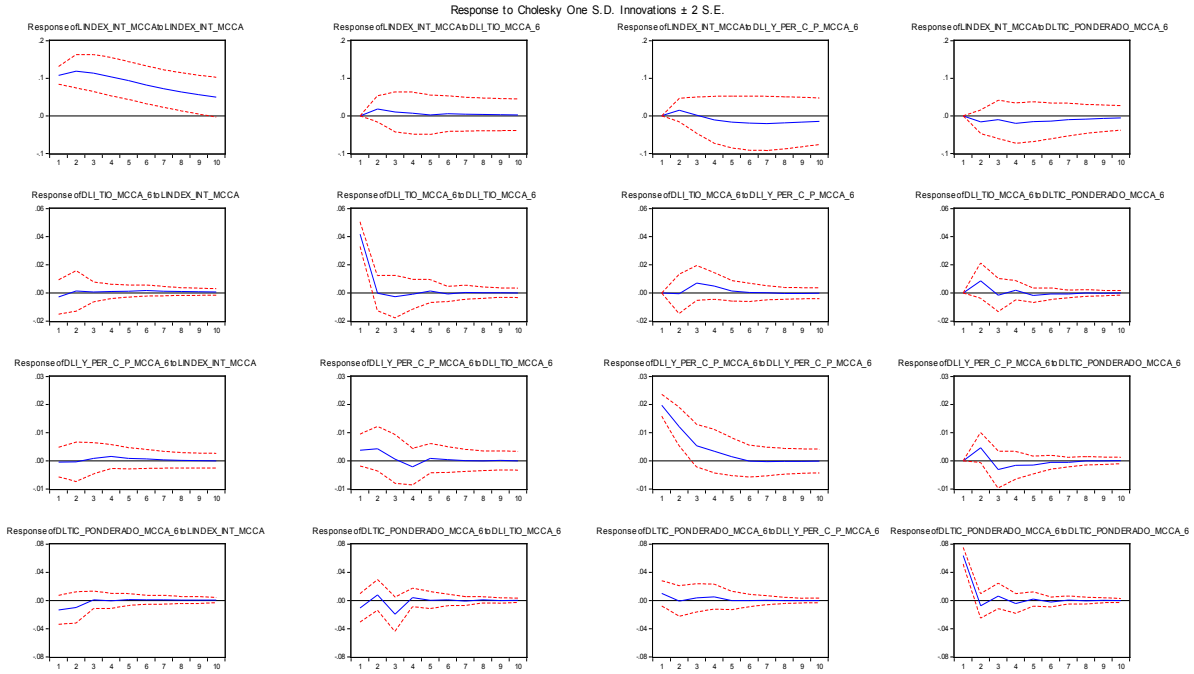
c) MCCA_RD
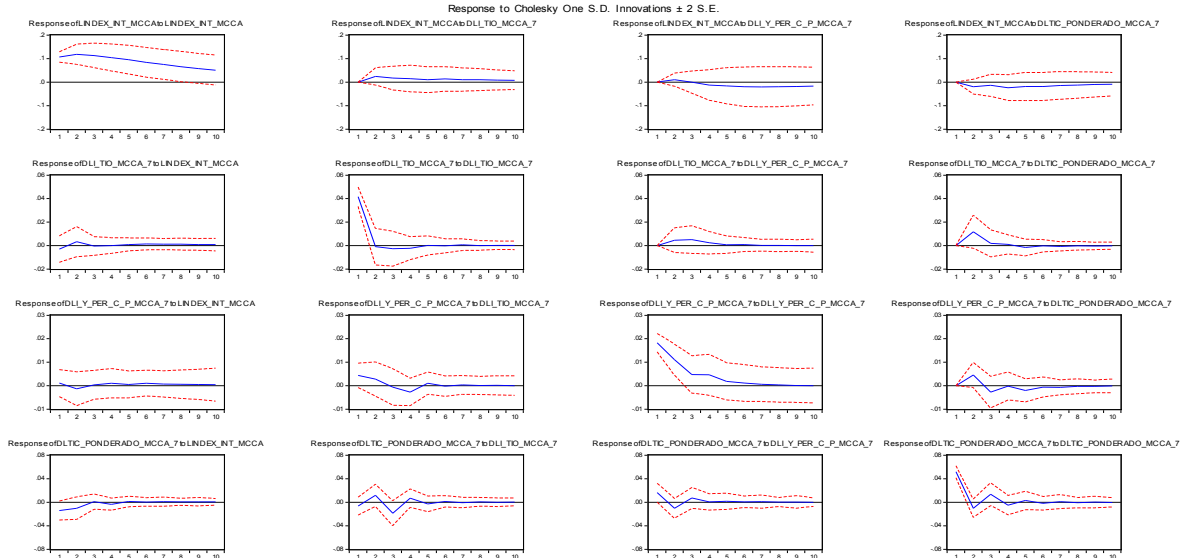

Fuente: Adaptado a partir de datos de Comisión Económica para América Latina Y el Caribe (2009).

\section{Cuadro 2 - Índex de Integración Institucional}

\begin{tabular}{|c|c|c|c|c|}
\hline $\begin{array}{l}\text { Etapa o nivel } \\
\text { de Integración } \\
\text { Económica }\end{array}$ & \multicolumn{2}{|c|}{$\begin{array}{l}\text { Primera Etapa de Integración Económica: Zona de li- } \\
\text { bre comercio: Libertad de comercio o libre movimien- } \\
\text { to de productos originarios de los estados miembros del } \\
\text { proceso de integración }\end{array}$} & Año & SCORE \\
\hline \multirow[t]{5}{*}{$\begin{array}{l}\text { PRIMER PERI- } \\
\text { ODO -1951 } \\
\text { a 1991- SUB- } \\
\text { STITUCIÓN } \\
\text { DE IMPORTA- } \\
\text { CIONES }\end{array}$} & \multirow[t]{5}{*}{$\begin{array}{l}\text { PRIMERA FASE: } \\
\text {-1951 a 1961- } \\
\text { : CARTA DE } \\
\text { ODECA (1951) }\end{array}$} & \multirow{2}{*}{$\begin{array}{l}\text { 1) Acuerdo Regional para la } \\
\text { Importación Temporal de Vehículos } \\
\text { de Carretera (1956): Admitir en } \\
\text { Franquicia temporal a vehículos } \\
\text { matriculados en uno de los Estados } \\
\text { Miembros (Art. II). } \\
\text { 2) Acuerdo Centroamericano sobre } \\
\text { Circulación por Carretera (1958). }\end{array}$} & 1951 & 0.00000 \\
\hline & & & 1952 & 0.00000 \\
\hline & & $\begin{array}{l}\text { 3) Acuerdo Centroamericano sobre } \\
\text { Señales Viales Uniformes (1958) }\end{array}$ & 1953 & 0.00000 \\
\hline & & \multirow[b]{2}{*}{$\begin{array}{l}\text { 4) Tratado Multilateral de Libre } \\
\text { Comercio e Integración Económica } \\
\text { Centroamericana (1958): Régi- } \\
\text { men de libre intercambio (Art. I), } \\
\text { oposición a prácticas discrimina- } \\
\text { torias (Cap. II), tránsito internac- } \\
\text { ional y comunicaciones (Cap. III } \\
\text { y V), oposición a subsidios a la } \\
\text { exportación y al comercio desleal } \\
\text { (Cap. IV), lista de bienes libres } \\
\text { de gravámenes -listado positivo-. } \\
\text { Anexo (A). }\end{array}$} & 1954 & 0.00000 \\
\hline & & & 1955 & 0.00000 \\
\hline
\end{tabular}




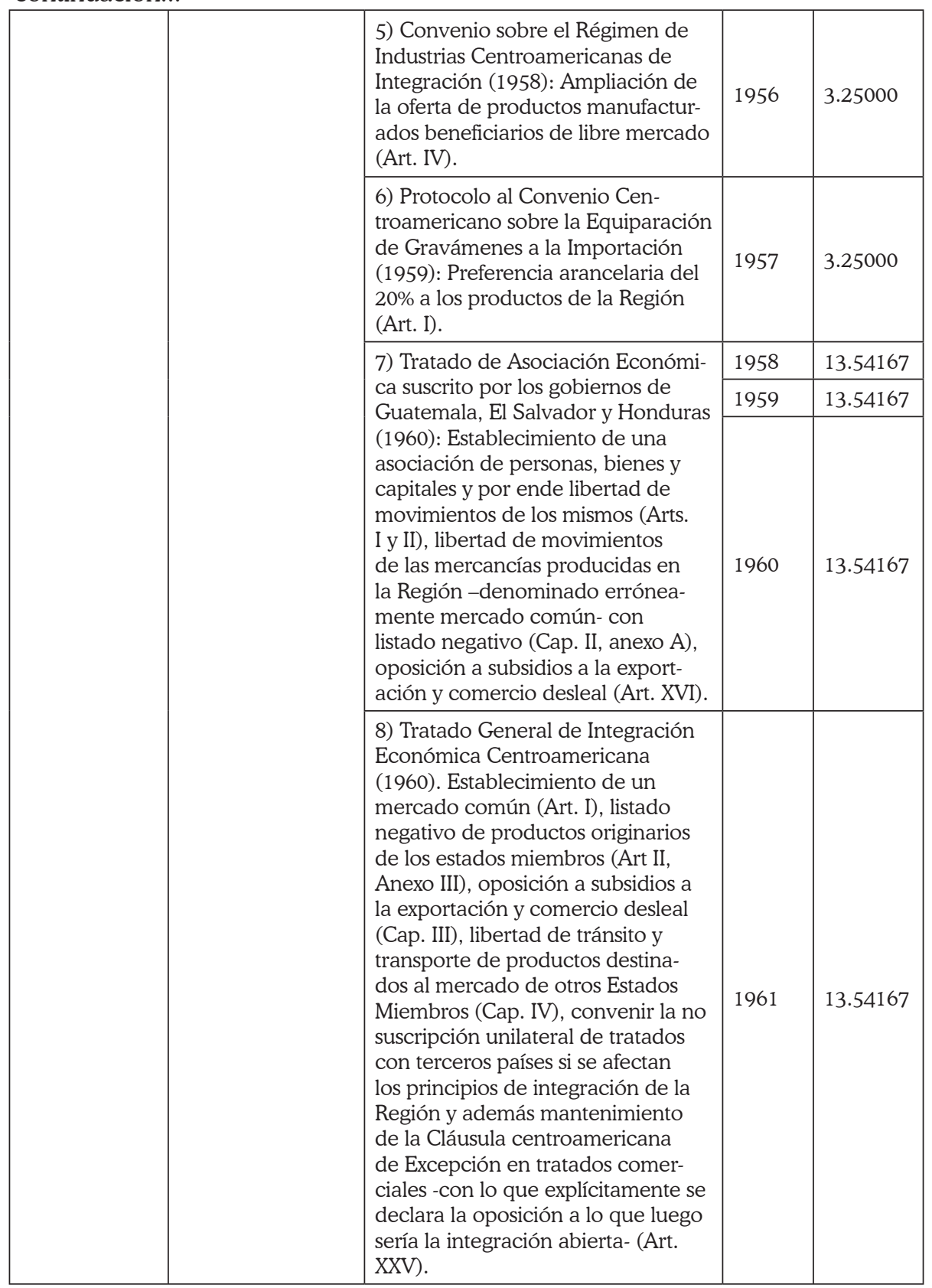




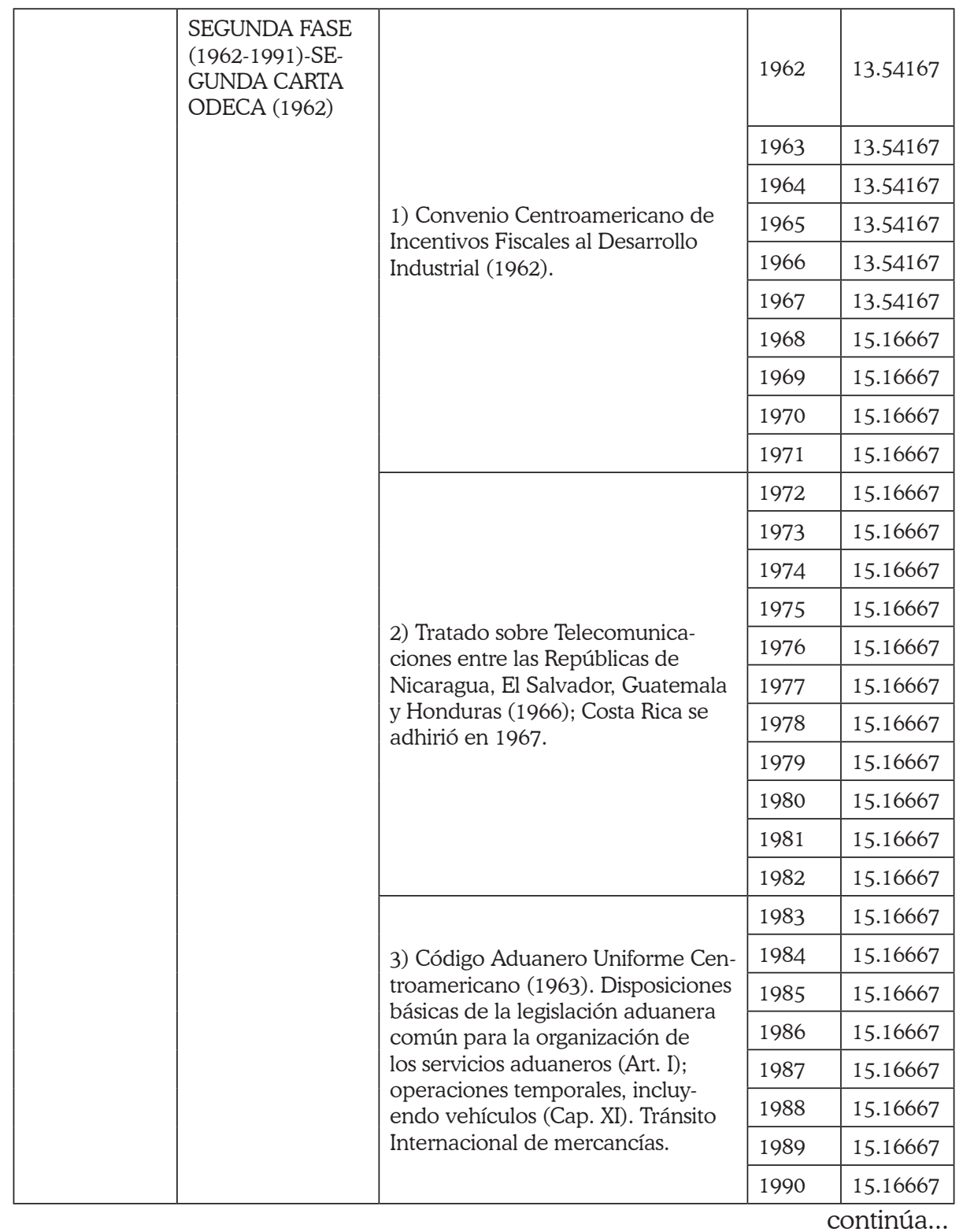


continuación...

\begin{tabular}{|c|c|c|c|c|}
\hline \multirow[t]{11}{*}{$\begin{array}{l}\text { SEGUNDO } \\
\text { PERÍODO- } \\
\text { 1991-AC- } \\
\text { TUALIDAD- } \\
\text { INSERCIÓN } \\
\text { EN LA } \\
\text { ECONOMÍA } \\
\text { INTERNAC- } \\
\text { IONAL }\end{array}$} & \multirow[t]{7}{*}{$\begin{array}{l}\text { PRIMERA FASE } \\
\text { (1991-1997) } \\
\text { PROTOCOLO } \\
\text { DE LA CARTA } \\
\text { ODECA (1991) O } \\
\text { PROTOCOLO DE } \\
\text { TEGUCIGALPA }\end{array}$} & \multirow{7}{*}{$\begin{array}{l}\text { 1) Protocolo al Tratado de inte- } \\
\text { gración Económica Centroamericana } \\
\text { - Protocolo de Guatemala-(1993): } \\
\text { Perfeccionamiento de la zona libre } \\
\text { de comercio (Art.7), oposición a } \\
\text { los subsidios y subvenciones a la } \\
\text { exportación y al dumping (Art. 8), } \\
\text { desarrollo de la infraestructura } \\
\text { física y servicios y libre tránsito } \\
\text { de las mercaderías través de los } \\
\text { territorios de los Estados Miembros } \\
\text { (Art.28). } \\
\text { 2) - Protocolo de Modificación } \\
\text { al Código Aduanero Uniforme } \\
\text { Centroamericano (1993): Las } \\
\text { disposiciones regirán en todas } \\
\text { las actividades aduaneras que se } \\
\text { efectúen en la región y sus normas } \\
\text { y las disposiciones legales de cada } \\
\text { país que se deriven de ellas serán } \\
\text { aplicables a personas, mercancía y } \\
\text { medio de transporte que cruce las } \\
\text { fronteras aduaneras de los países } \\
\text { signatarios sin importar su origen } \\
\text { o procedencia (Art. 1); deroga } \\
\text { el Código Aduanero Uniforme } \\
\text { Centroamericano de 1963 (Cap. } \\
\text { Transitorio). } \\
\text { 3) Protocolo al Tratado Centroameri- } \\
\text { cano de Telecomunicaciones (1995): } \\
\text { Mejorar y Modernizar las telecomu- } \\
\text { nicaciones en la Región (Art. 4). }\end{array}$} & 1991 & 15.16667 \\
\hline & & & 1992 & 15.16667 \\
\hline & & & 1993 & 18.41667 \\
\hline & & & 1994 & 18.41667 \\
\hline & & & 1995 & 18.41667 \\
\hline & & & 1996 & 18.41667 \\
\hline & & & 1997 & 18.41667 \\
\hline & \multirow[t]{4}{*}{$\begin{array}{l}\text { SEGUNDA FASE } \\
\text { (1998-PRESENTE) } \\
\text { XIX REUNIÓN DE } \\
\text { PRESIDENTES } \\
\text { (1998) O DE- } \\
\text { CLARACIÓN DE } \\
\text { PANAMÁ }\end{array}$} & \multirow{4}{*}{$\begin{array}{l}\text { 1) Tratado sobre Inversión y Comer- } \\
\text { cio de Servicios entre las Repúblicas } \\
\text { de Costa Rica, El Salvador, Guate- } \\
\text { mala, Honduras y Nicaragua (2002; } \\
\text { en } 2003 \text { en proceso de ratificación): } \\
\text { Liberalización del comercio de los } \\
\text { servicios y la inversión entre los } \\
\text { Estados Miembros, consistente con } \\
\text { el Tratado General de Integración } \\
\text { Económica Centroamericana } \\
\text { (1960) }\end{array}$} & 1998 & 18.41667 \\
\hline & & & 1999 & 18.41667 \\
\hline & & & 2000 & 18.41667 \\
\hline & & & 2001 & 18.41667 \\
\hline
\end{tabular}




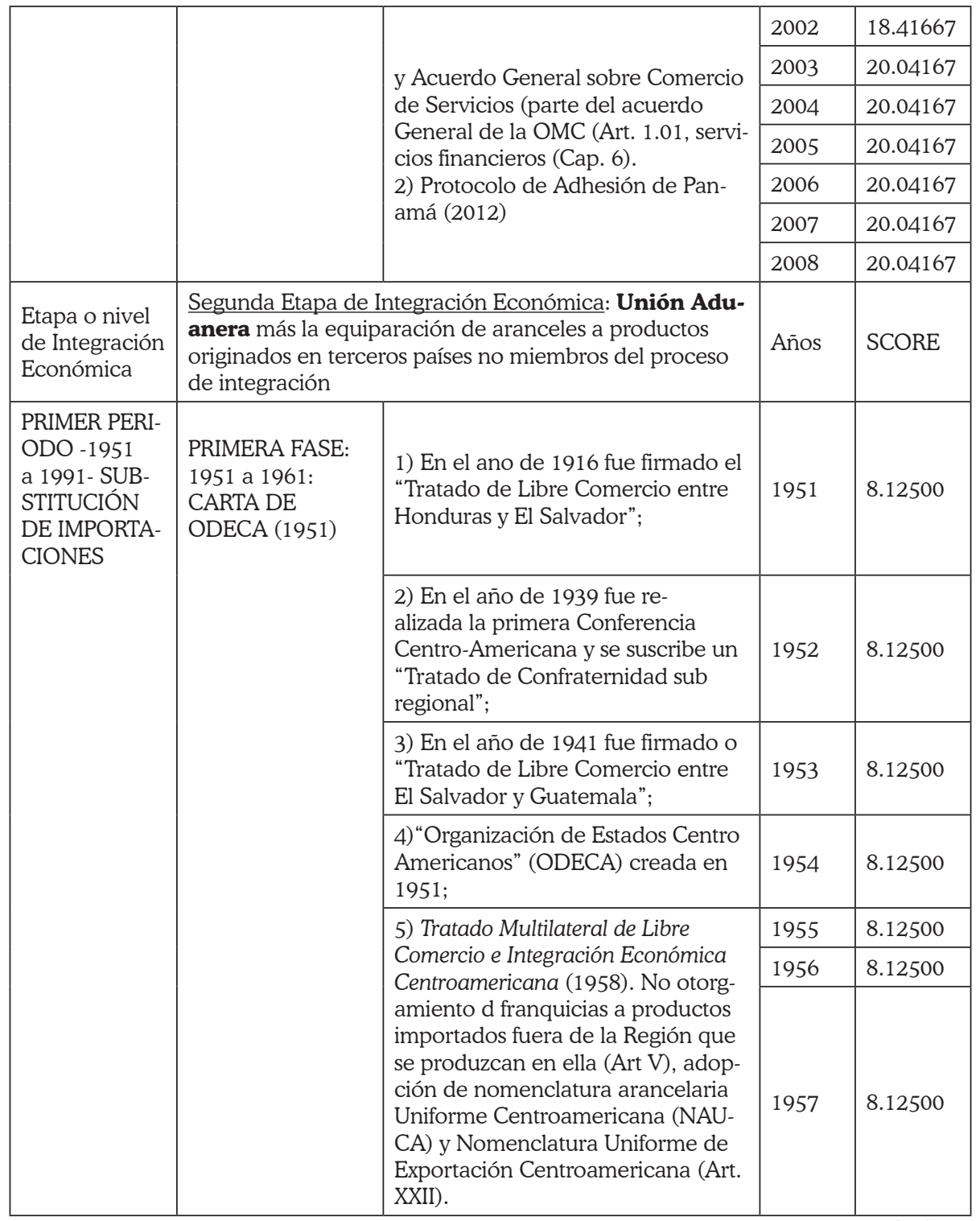

continúa... 


\begin{tabular}{|c|c|c|c|}
\hline & $\begin{array}{l}\text { 6) Convenio sobre Régimen de } \\
\text { Industrias Centroamericanas de } \\
\text { Integración (1958): Equiparación } \\
\text { de gravámenes a la importación de } \\
\text { mercancías similares o sucedáneas } \\
\text { de las industrias centroamericanas } \\
\text { de integración (Art. V), no otorg- } \\
\text { amiento de franquicias o rebajas } \\
\text { por debajo del aforo común a la } \\
\text { importación fuera de la Región de } \\
\text { mercancías similares o sucedáneas } \\
\text { de las industrias centroamericanas } \\
\text { de integración (Art. VII). }\end{array}$ & 1958 & 14.08333 \\
\hline & \multirow[b]{2}{*}{$\begin{array}{l}\text { 7) Convenio Centroamericano } \\
\text { de Equiparación de Gravámenes } \\
\text { sobre la Equiparación a la Import- } \\
\text { ación (1959): Equiparación de } \\
\text { gravámenes a la importación con } \\
\text { base en la Nomenclatura Arance- } \\
\text { laria Uniforme Centroamericana } \\
\text { (NAUCA -Art. 1). }\end{array}$} & 1959 & 18.41633 \\
\hline & & 1960 & 18.41633 \\
\hline \multirow[t]{7}{*}{\begin{tabular}{|l} 
SEGUNDA FASE \\
(1962-1991)-SE- \\
GUNDA CARTA \\
ODECA (1962
\end{tabular}} & \multirow{7}{*}{$\begin{array}{l}\text { 1) Código Aduanero Uniforme Cen- } \\
\text { troamericano (1963) (CAUCA) } \\
\text { 2) Convenio sobre el Régimen } \\
\text { Arancelario y Aduanero Centroamer- } \\
\text { icano (1984): Establecimiento del } \\
\text { Régimen Arancelario y Aduan- } \\
\text { ero Centroamericano (Art.) entre } \\
\text { sus componentes esta Arancel } \\
\text { Centroamericano de Importación- } \\
\text { Anexo A- Legislación Centroameri- } \\
\text { cana sobre el Valor Aduanero de } \\
\text { las Mercancías -Anexo B- Código } \\
\text { Aduanero Uniforme Centroameri- } \\
\text { cano (CAUCA) y su Reglamento } \\
\text { (RECAUCA) (Art. 2, Cap. III y } \\
\text { IV), regulación y otorgamiento } \\
\text { de franquicias y exenciones de } \\
\text { derechos arancelarios (Cap. V), } \\
\text { Opción de tomar otras medidas } \\
\text { compensatorias para contrarrestar } \\
\text { la competencia desleal de mer- } \\
\text { cancías provenientes de afuera de } \\
\text { la Región (Cap. VII), para fines de } \\
\text { unidad y uniformidad arancelaria } \\
\text { se tendrá como unidad de cuenta } \\
\text { el Peso Centroamericano (Art. 20). }\end{array}$} & 1962 & 18.41633 \\
\hline & & 1963 & 18.41633 \\
\hline & & 1964 & 18.41633 \\
\hline & & 1965 & 18.41633 \\
\hline & & 1966 & 18.41633 \\
\hline & & 1967 & 18.41633 \\
\hline & & 1968 & 18.41633 \\
\hline
\end{tabular}




\begin{tabular}{|c|c|c|c|c|}
\hline & & & 1969 & 18.41633 \\
\hline & & & 1970 & 18.41633 \\
\hline & & & 1971 & 18.41633 \\
\hline & & & 1972 & 18.41633 \\
\hline & & & 1973 & 18.41633 \\
\hline & & & 1974 & 18.41633 \\
\hline & & & 1975 & 18.41633 \\
\hline & & & 1976 & 18.41633 \\
\hline & & & 1977 & 18.41633 \\
\hline & & & 1978 & 18.41633 \\
\hline & & & 1979 & 18.41633 \\
\hline & & & 1980 & 18.41633 \\
\hline & & & 1981 & 18.41633 \\
\hline & & & 1982 & 18.41633 \\
\hline & & & 1983 & 18.41633 \\
\hline & & & 1984 & 18.41633 \\
\hline & & & 1985 & 18.41633 \\
\hline & & & 1986 & 18.41633 \\
\hline & & & 1987 & 18.41633 \\
\hline & & & 1988 & 18.41633 \\
\hline & & & 1989 & 18.41633 \\
\hline & & & 1990 & 18.41633 \\
\hline $\begin{array}{l}\text { SEGUNDO } \\
\text { PERÍODO- } \\
\text { 1991-AC- } \\
\text { TUALIDAD- } \\
\text { INSERCIÓN } \\
\text { EN LA } \\
\text { ECONOMÍA } \\
\text { INTERNAC- } \\
\text { IONAL }\end{array}$ & $\begin{array}{l}\text { PRIMERA FASE } \\
\text { (1991-1997) } \\
\text { PROTOCOLO DE }\end{array}$ & $\begin{array}{l}\text { 1) Protocolo al Tratado de inte- } \\
\text { gración Económica Centroameri- } \\
\text { cana- Protocolo de Guatemala- } \\
\text { (1993): Perfeccionamiento del } \\
\text { arancel centroamericano de im- }\end{array}$ & 1991 & 23.83300 \\
\hline & LA CARTA DE & portación (Art. 10), establecimiento & 1992 & 23.83300 \\
\hline & PROTOCOLO DE & por medio del servicio aduan- & 1993 & 23.83300 \\
\hline & TEGUCIGALPA & ero común con procedimientos, & 1994 & 23.83300 \\
\hline & & uniformes (Arts. 15-17). & 1995 & 23.83300 \\
\hline & & & 1996 & 23.83300 \\
\hline & & & 1997 & 23.83300 \\
\hline & & & 1998 & 23.83300 \\
\hline
\end{tabular}




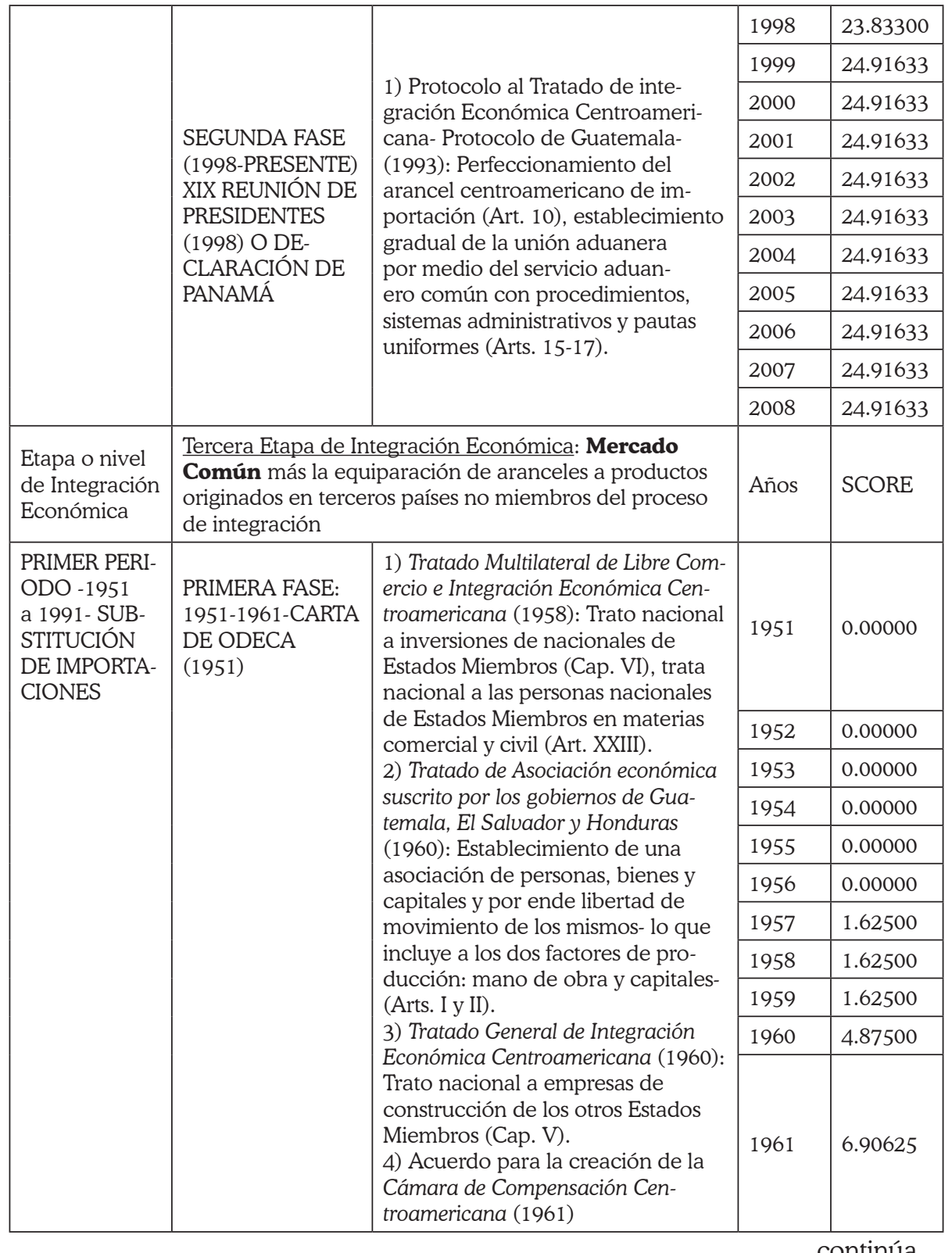




\begin{tabular}{|c|c|c|c|}
\hline \multirow{29}{*}{$\begin{array}{l}\text { SEGUNDA FASE: } \\
\text { 1962-1991-SEG- } \\
\text { UNDA CARTA DE } \\
\text { ODECA (1962) }\end{array}$} & \multirow{29}{*}{$\begin{array}{l}\text { 1) Convenio sobre el ejercicio de } \\
\text { Profesiones Universitarias y Recono- } \\
\text { cimiento de Estudios Universitarios } \\
\text { (1962) } \\
\text { 2) Segunda Carta de la ODECA } \\
\text { (1962): Creación del Consejo } \\
\text { Económico Centroamericano, } \\
\text { para entre otros aspectos, coordi- } \\
\text { nación de las políticas monetarias y } \\
\text { cambiaras. } \\
\text { 3) Acuerdo para el Establecimiento } \\
\text { de la Unión Monetaria Centroamer- } \\
\text { icana (1964) Y Acuerdo Monetario } \\
\text { Centroamericano (1974). } \\
\text { 4) Convenio sobre el Régimen } \\
\text { Arancelario y Aduanero Cen- } \\
\text { troamericano (1984): Para fines de } \\
\text { unidad y uniformidad arancelaria } \\
\text { se tendrá como unidad de cuenta } \\
\text { el Peso Centroamericano, con el } \\
\text { valor que le fije el Consejo Mon- } \\
\text { etario Centroamericano (Art 20). }\end{array}$} & 1962 & 14.48958 \\
\hline & & 1963 & 14.48958 \\
\hline & & 1964 & 18.82292 \\
\hline & & 1965 & 18.82292 \\
\hline & & 1966 & 18.82292 \\
\hline & & 1967 & 18.82292 \\
\hline & & 1968 & 18.82292 \\
\hline & & 1969 & 18.82292 \\
\hline & & 1970 & 18.82292 \\
\hline & & 1971 & 18.82292 \\
\hline & & 1972 & 18.82292 \\
\hline & & 1973 & 18.82292 \\
\hline & & 1974 & 18.82292 \\
\hline & & 1975 & 18.82292 \\
\hline & & 1976 & 18.82292 \\
\hline & & 1977 & 18.82292 \\
\hline & & 1978 & 18.82292 \\
\hline & & 1979 & 18.82292 \\
\hline & & 1980 & 18.82292 \\
\hline & & 1981 & 18.82292 \\
\hline & & 1982 & 18.82292 \\
\hline & & 1983 & 18.82292 \\
\hline & & 1984 & 18.82292 \\
\hline & & 1985 & 18.82292 \\
\hline & & 1986 & 18.82292 \\
\hline & & 1987 & 18.82292 \\
\hline & & 1988 & 18.82292 \\
\hline & & 1989 & 18.82292 \\
\hline & & 1990 & 18.82292 \\
\hline
\end{tabular}


continuación...

\begin{tabular}{|c|c|c|c|c|}
\hline \multirow[t]{15}{*}{$\begin{array}{l}\text { SEGUNDO } \\
\text { PERÍODO- } \\
\text { 1991-AC- } \\
\text { TUALIDAD- } \\
\text { INSERCIÓN } \\
\text { EN LA } \\
\text { ECONOMÍA } \\
\text { INTERNAC- } \\
\text { IONAL }\end{array}$} & \multirow{7}{*}{$\begin{array}{l}\text { PRIMERA FASE } \\
\text { (1991-1997)-PRO- } \\
\text { TOCOLO DE } \\
\text { LA CARTA DE } \\
\text { ODECA (1991) } \\
\text { PROTOCOLO DE } \\
\text { TEGUCIPALPA }\end{array}$} & \multirow{7}{*}{$\begin{array}{l}\text { 1) Protocolo al Tratado de Inte- } \\
\text { gración Económica Centroameri- } \\
\text { cana-Protocolo de Guatemala- } \\
\text { (1993): Búsqueda consistente del } \\
\text { equilibrio macroeconómico y } \\
\text { estabilidad interna y externa de las } \\
\text { economías (Art. 4); armonización } \\
\text { de las políticas para las relaciones } \\
\text { comerciales con terceros, acceso } \\
\text { a mercados, diversificación de la } \\
\text { producción exportable y capacidad } \\
\text { de negociación - con lo que se } \\
\text { reconoce el período de negociación } \\
\text { abierta - Arts. 11-14 y Cap. III) libre } \\
\text { movilidad de factores productivos: } \\
\text { mano de obra y capital (Art. 18), } \\
\text { integración monetaria y financiera y } \\
\text { armonización de las políticas mac- } \\
\text { roeconómicas: monetaria y fiscal, } \\
\text { para lograr la estabilidad interna } \\
\text { y externa (Art. 19), perfeccion- } \\
\text { amiento de las políticas sectoriales } \\
\text { (Cap. II), Libre contratación de } \\
\text { transporte (Art. 28), armonización } \\
\text { de legislación en materia de banca, } \\
\text { entidades financieras, bursátiles, } \\
\text { seguros, propiedad intelectual e } \\
\text { industrial, registros sanitarios y } \\
\text { autenticidad de actos y contratos } \\
\text { (Art. 30), armonización para el ejer- } \\
\text { cicio de Profesiones Universitarias } \\
\text { y Reconocimiento de Profesiones } \\
\text { universitarias (1962) (Art. 31). }\end{array}$} & 1991 & 23.15625 \\
\hline & & & 1992 & 23.15625 \\
\hline & & & 1993 & 23.15625 \\
\hline & & & 1994 & 23.15625 \\
\hline & & & 1995 & 23.15625 \\
\hline & & & 1996 & 23.15625 \\
\hline & & & 1997 & 23.15625 \\
\hline & $\begin{array}{l}\text { SEGUNDA FASE } \\
\text { (1998-PRE- } \\
\text { SENTE)- XIX RE- } \\
\text { UNIÓN DE PRESI- } \\
\text { DENTES (1998) O } \\
\text { DECLARACIÓN } \\
\text { DE PANAMÁ }\end{array}$ & & 1998 & 24.23958 \\
\hline & & & 1999 & 24.23958 \\
\hline & & & 2000 & 24.23958 \\
\hline & & & 2001 & 24.23958 \\
\hline & & & 2002 & 24.23958 \\
\hline & & & 2003 & 24.23958 \\
\hline & & & 2004 & 24.23958 \\
\hline & & & 2005 & 24.23958 \\
\hline
\end{tabular}


conclusión.

\begin{tabular}{|c|c|c|c|}
\hline & & & \\
\hline & & 2006 & 24.23958 \\
\hline & & 2007 & 24.23958 \\
\hline & & 2008 & 24.23958 \\
\hline $\begin{array}{l}\text { Etapa o nivel } \\
\text { de Integración } \\
\text { Económica }\end{array}$ & $\begin{array}{l}\text { Cuarte Etapa de Integración Económica: Unión } \\
\text { Económica Total: es un Mercado Común adicionando } \\
\text { la identidad de las políticas económicas y sociales y } \\
\text { órganos e instituciones con representación de la unión o } \\
\text { capacidad de iniciativa y decisión }\end{array}$ & Años & SCORE \\
\hline \multirow{2}{*}{$\begin{array}{l}\text { PRIMER PERI- } \\
\text { ODO -1951 } \\
\text { a } 1991-\text { SUB- } \\
\text { STITUCIÓN } \\
\text { DE IMPORTA- } \\
\text { CIONES }\end{array}$} & $\begin{array}{l}\text { PRIMERA FASE: } \\
\text { 1951 a 1961: } \\
\text { CARTA DE } \\
\text { ODECA (1951) }\end{array}$ & & 0.000000 \\
\hline & $\begin{array}{l}\text { SEGUNDA FASE } \\
\text { (1962-1991)-SEG- } \\
\text { UNDA CARTA DE } \\
\text { ODECA }(1962\end{array}$ & & 0.000000 \\
\hline \multirow{2}{*}{$\begin{array}{l}\text { SEGUNDO } \\
\text { PERÍODO- } \\
\text { 1991-AC- } \\
\text { TUALIDAD- } \\
\text { INSERCIÓN } \\
\text { EN LA } \\
\text { ECONOMÍA } \\
\text { INTERNAC- } \\
\text { IONAL }\end{array}$} & $\begin{array}{l}\text { PRIMERA FASE } \\
(1991-1997) \\
\text { PROTOCOLO DE } \\
\text { LA CARTA DE } \\
\text { ODECA (1991) O } \\
\text { PROTOCOLO DE } \\
\text { TEGUCIGALPA }\end{array}$ & & 0.000000 \\
\hline & $\begin{array}{l}\text { SEGUNDA FASE } \\
\text { (1998-PRESENTE) } \\
\text { XIX REUNIÓN DE } \\
\text { PRESIDENTES } \\
\text { (1998) O DE- } \\
\text { CLARACIÓN DE } \\
\text { PANAMÁ }\end{array}$ & & 0.000000 \\
\hline
\end{tabular}

Fuente: Adaptado a partir de Dorrucci et al. (2002), SIECA; ASIES; ADAPCCA; UE; GOPA (2010).

Recebido em: 26/12/2016. Aceito em: 07/03/2017. 